\title{
rSac3, a novel Sac domain phosphoinositide phosphatase, promotes neurite outgrowth in PC12 cells
}

\author{
Yiyuan Yuan ${ }^{1}$, Xiang Gao ${ }^{1}$, Ning Guo ${ }^{2,4}$, Hui Zhang ${ }^{3}$, Zhiqin Xie ${ }^{1}$, Meilei Jin², Baoming Li ${ }^{3}$, Lei Yu ${ }^{4}$, Naihe Jing ${ }^{1}$ \\ ${ }^{1}$ Laboratory of Molecular Cell Biology and Key Laboratory of Stem Cell Biology, Institute of Biochemistry and Cell Biology, Shanghai \\ Institutes for Biological Sciences, Chinese Academy of Sciences, 320 Yue yang Road, Shanghai 200031, China; ${ }^{2}$ Research Center \\ of Biotechnology, Shanghai Institutes for Biological Sciences, Chinese Academy of Sciences, 500 Cao bao Road, Shanghai 200233, \\ China; ${ }^{3}$ Laboratory of Higher Brain Functions, Institute of Neurobiology, Institutes of Brain Science, Fudan University, 138 Yi xue \\ yuan Road, Shanghai 200032, China; ${ }^{4}$ Department of Genetics and Center of Alcohol Studies, Rutgers University, 145 Bevier Road, \\ Piscataway, NJ 08854, USA
}

Sac domain-containing proteins belong to a newly identified family of phosphoinositide phosphatases (the PIPPase family). Despite well-characterized enzymatic activity, the biological functions of this mammalian Sac domain PIPPase family remain largely unknown. We identified a novel Sac domain-containing protein, rat Sac3 (rSac3), which is widely expressed in various tissues and localized to the endoplasmic reticulum, Golgi complex and recycling endosomes. rSac3 displays PIPPase activity with $\mathrm{PI}(3) \mathrm{P}, \mathrm{PI}(4) \mathrm{P}$ and $\mathrm{PI}(3,5) \mathrm{P}_{2}$ as substrates in vitro, and a mutation in the catalytic core of the Sac domain abolishes its enzymatic activity. The expression of $\mathrm{rSac} 3$ is upregulated during nerve growth factor (NGF)-stimulated PC12 cell neuronal differentiation, and overexpression of this protein promotes neurite outgrowth in PC12 cells. Conversely, inhibition of rSac3 expression by antisense oligonucleotides reduces neurite outgrowth of NGFstimulated PC12 cells, and the active site mutation of rSac3 eliminates its neurite-outgrowth-promoting activity. These results indicate that $\mathrm{rSac} 3$ promotes neurite outgrowth in differentiating neurons through its PIPPase activity, suggesting that Sac domain PIPPase proteins may participate in forward membrane trafficking from the endoplasmic reticulum and Golgi complex to the plasma membrane, and may function as regulators of this crucial process of neuronal cell growth and differentiation.

Keywords: PIPPase, intracellular membrane trafficking, neurite outgrowth

Cell Research (2007) 17: 919-932. doi: 10.1038/cr.2007.82; published online 1 October 2007

\section{Introduction}

Intracellular membrane trafficking is an important cellular process of eukaryotic cells. It is essential to maintain a proper composition of various cell organelles and to transport various molecules to appropriate compartments

\footnotetext{
Corresponding authors: Meilei Jin, Baoming Li, Lei Yu, Naihe Jing Correspondence: Naihe Jing

Tel: +86-21-5492-1381; Fax: +86-21-5492-1011

E-mail: njing@sibs.ac.cn

Received 8 June 2007; revised 12 June 2007; accepted 19 June 2007; published online 1 October 2007
}

within the cell. Membrane transport between various intracellular compartments is achieved mainly by two pathways: endocytic recycling and biosynthetic secretion. Endocytic recycling has a crucial role in the internalization of cell-surface proteins, lipids and soluble molecules [1]. Among all the endocytic pathways, clathrin-coated endocytosis is the most significant [2]. Various proteins, such as endophilin [3], dynamin [4, 5] and synaptojanin $1[6]$, are required in this process. Newly formed early endosomes either recycle to the plasma membrane (PM) through recycling endosomes or are transported to late endosomes and lysosomes for degradation [7]. Biosynthetic secretion is another process that contributes to the cell-surface growth. 
This exocytic pathway consists of a series of membranebounded compartments, such as the endoplasmic reticulum (ER), intermediate vesicle and Golgi complex. Membrane trafficking between the ER and Golgi complex is carried out by two classes of cytosolic coat proteins, COP I and COP II [8], and the four-phosphate-adaptor proteins are required for the generation of constitutive post-Golgi carries [9]. However, how vesicles are transported from the Golgi complex to the PM is still unclear.

Of all the proteins known to be associated with membrane trafficking, Sac domain proteins constitute a newly identified family that plays crucial roles in intracellular vesicle trafficking. The Sac domain is mainly localized at the $\mathrm{N}$-terminus of the protein, and it represents a protein domain that is homologous to the yeast protein Sac1p [10], which possesses intrinsic phosphoinositide phosphatase (PIPPase) activity. This family can be further divided into two subfamilies. Proteins in one subfamily contain the Sac domain and the type II phosphatidylinositol phosphatase 5-phosphatase domain, and members include mammalian synaptojanin 1 [11] and synaptojanin 2 [12], and yeast Inp51p, Inp52p and Inp53p [13]. Synaptojanin 1 is enriched in nerve terminals and associates with membranes that are coated with clathrin [11]. The C-terminal region of synaptojanin 1 may interact with the SH3 domain of different proteins [14-18]. Mice that are deficient in synaptojanin 1 have elevated levels of $\mathrm{PI}(4,5) \mathrm{P}_{2}$ and $\mathrm{PI}(3,4,5) \mathrm{P}_{3}$ in the brain cytosol and accumulate coated vesicles at nerve terminals, suggesting that synaptojanin 1 functions in recycling vesicles back to the synaptic vesicle pool [19]. Synaptojanin 2 is expressed as multiple alternative splice forms in various tissues [12], and may be involved in clathrin-coated pit formation and lipid hydrolysis, which are required during early clathrin-mediated endocytosis [20].

The other subfamily of Sac domain-containing PIPPases includes two yeast proteins, Sac1p [21] and Fig4p [22], as well as several mammalian counterparts, hSac1 [23], hSac2 [24] and a yet-to-be-characterized putative protein KIAA0274. Yeast Sac1p was cloned as a suppressor of actin mutations [21]. It localizes in the ER and Golgi complex, and regulates a PI(4)P pool that is important for Golgi trafficking in yeast $[25,26]$. Yeast $\mathrm{Sac} 1 \mathrm{p}$ is also an important factor in efficient ATP uptake from cytosolic microsomes into the ER lumen $[27,28]$. Fig4p has been identified as a pheromone-regulated or induced gene product, and localizes in the limiting membrane of yeast vacuoles. It interacts with Vac14p and forms the Vac14p-Fig $4 p$ complex. This complex controls the hyperosmotic shock-induced increase in $\mathrm{PI}(3,5) \mathrm{P}_{2}$ levels to maintain the vacuole size $[29,30]$. hSac1 localizes to the ER and Golgi apparatus, and could interact with members of the COP I complex through its Cterminal KXKXXX motif [23]. hSac2 is a $120-\mathrm{kD}$ a protein, and is the first Sac domain-containing protein that has been shown to possess inositol polyphosphate 5-phosphatase activity [24]. Despite well-characterized enzymatic activity, the biological functions of this mammalian Sac domain PIPPase subfamily remain largely unknown.

In this study, we identified a novel Sac domain-containing phosphoinositide phosphatase, rat Sac3 (rSac3). It localizes to the ER, Golgi complex and recycling endosomes. As a PIPPase, it played an important role in the neurite outgrowth of nerve growth factor (NGF)-stimulated PC12 cells.

\section{Material and Methods}

\section{Low-abundance cDNA sublibrary}

Sprague-Dawley rats (from the Shanghai Laboratory Animal Center, Shanghai Institutes for Biological Sciences, Chinese Academy of Sciences, Shanghai, China) were killed at postnatal day 0.5 and brain tissues were collected for RNA extraction using Oligotex reagent (Qiagen, Valencia, CA, USA). Two micrograms poly(A) ${ }^{+}$RNA were reverse transcribed with Superscript II reverse transcriptase (Gibco/ BRL, Rockville, MD, USA), and cDNAs were labeled with $\alpha{ }^{32} \mathrm{P}-$ dATP as the probe using a random primer strategy. A brain cDNA library of 8-week-old male rats (Gibco/BRL) was screened with the probe as described [31]. The non-hybridizing clones (approximately 10000 clones) were selected to construct a low-abundance cDNA sublibrary and used for differential screening.

\section{Cloning of $r \mathrm{Sac} 3 \mathrm{cDNA}$}

The rat low-abundance cDNA sublibrary was screened as previously described [31]. In brief, adult male Sprague-Dawley rats (200-250 g, purchased from the Shanghai Laboratory Animal Center) were randomly assigned into two groups. The training group received step-down inhibitory avoidance training and the control group received sham training (with no electric shock). The rats were anesthetized and decapitated $6 \mathrm{~h}$ after training and hippocampal tissues were collected for RNA extraction using Oligotex reagent (Qiagen, Valencia, CA, USA). Poly(A)+ RNA $(2 \mu \mathrm{g})$ from each group was reverse transcribed with Superscript II reverse transcriptase (Gibco/BRL, Rockville, MD, USA) and cDNAs from the control and training groups were labeled with $\alpha-{ }^{32} \mathrm{P}-\mathrm{dATP}$ by random priming. These radioactive probes were used to hybridize duplicate filters of the low-abundance cDNA sublibrary, and differentially expressed clones (positive versus negative) were isolated and subjected to DNA sequencing. Sequence analysis revealed a new gene fragment that is homologous to human KIAA0274. The full-length cDNA of this new gene was isolated by rescreening the same library, and by RT-PCR amplifying the 5'-end fragment with the forward primer 5'-GCCATGCCCACGGCCGCTGCCCCCATCATC-3' and the reverse primer 5'-GGGTGAGTAATCCGAACAGAG-3'. The amplification was conducted in a thermal cycler (Minicycler ${ }^{\mathrm{TM}}$, PTC-150, MJ Research, Inc., MA, USA) for 30 cycles of $94{ }^{\circ} \mathrm{C}$ for $45 \mathrm{~s}, 56{ }^{\circ} \mathrm{C}$ for $45 \mathrm{~s}$ and $72{ }^{\circ} \mathrm{C}$ for 1 min using Pfu Taq polymerase (BioAsia Research Inc., Shanghai, China). rSac3 cDNA was cloned into the pBluescript II-SK vector (Stratagene, La Jolla, CA, USA), and sequenced by BioAsia Research Inc. The cDNA sequence was deposited in GenBank with the accessory number DQ666853, and was used to search for homol- 
ogy and chromosomal localization against the GenBank entries using the NCBI BLAST algorithm.

\section{Northern blot analysis}

Northern blot analysis was carried out as previously described [32]. In brief, total RNA $(40 \mu \mathrm{g})$ from different rat tissues was subjected to electrophoresis and transferred onto an $\mathrm{N}+$ nylon membrane. The hybridization probes were ${ }^{32} \mathrm{P}$-labeled by random priming using a 0.65 -kb fragment of rSac3 cDNA (449 to 1101 bp protein-coding region) and a $0.2-\mathrm{kb}$ cDNA fragment of rat $18 \mathrm{~S}$ RNA. The RNA blots were hybridized at $65{ }^{\circ} \mathrm{C}$ in a hybridization solution containing $0.2 \mathrm{M} \mathrm{Na}_{3} \mathrm{PO}_{4}$ ( $\mathrm{pH} 7.2$ ), 1 mM EDTA (pH 8.0), 1\% BSA, 7\% SDS, $15 \%$ formamide and $100 \mu \mathrm{g} / \mathrm{ml}$ denatured salmon sperm DNA. After overnight hybridization, blots were washed for $1 \mathrm{~h}$ at $65^{\circ} \mathrm{C}$, and were exposed to X-ray films overnight at $-80{ }^{\circ} \mathrm{C}$. The hybridized signal was visualized using SNAPscan 1212 (AGFA Corp., Ridgefield Park, NJ, USA).

\section{Western blot analysis}

Western blot analysis was carried out as previously described [32]. In brief, tissue samples (60 $\mu \mathrm{g}$ protein per lane) from adult male Sprague-Dawley rats were subjected to electrophoresis and transferred to an Immobilon-P transfer membrane (Millipore Corporation, Bedford, MA, USA) at $50 \mathrm{~V}$ constant voltage for $3 \mathrm{~h}$ at $4{ }^{\circ} \mathrm{C}$. Membranes were blocked in 5\% non-fat milk in PBS for $1 \mathrm{~h}$ at room temperature and incubated with an anti-rSac3 antibody (1:1000) overnight at $4{ }^{\circ} \mathrm{C}$. Membranes were washed three times, then incubated for $1 \mathrm{~h}$ with a secondary antibody, goat anti-rabbit IgG conjugated with HRP (1:5000, Calbiochem, La Jolla, CA, USA). The signal was detected using the ECL method. The loading control experiment was performed with the monoclonal anti- $\beta$-actin antibody (1:5000, Sigma, Saint Louis, MO, USA) and the anti-GAPDH antibody (1:5000, KangChen Bio-tech, Shanghai, China).

\section{Cell culture}

Monkey kidney COS-7 cells were maintained in DMEM (Dulbecco-modified Eagle medium) supplemented with $10 \%$ fetal bovine serum at $37{ }^{\circ} \mathrm{C}$ with $5 \% \mathrm{CO}_{2}$. Undifferentiated PC12 cells were maintained in DMEM supplemented with 10\% horse serum (Gibco, Paisley, UK) and 5\% fetal calf serum (Hyclone, Logan, UT, USA). The construct transfection was performed using FuGene 6 (Roche Applied Science, Indianapolis, IN, USA) according to the manufacturer's instructions. To generate PC12 lines that stably express HA-tagged rSac3 (HA-rSac3), the construct and vector controls were transfected and selected in the presence of $500 \mu \mathrm{g} / \mathrm{ml} \mathrm{G} 418$. Resistant clones were routinely maintained in the medium containing G418. For differentiation, cells were seeded at a density of 2000 cells $/ \mathrm{cm}^{2}$ in a 35-mm dish pre-coated with gelatin, with DMEM medium containing $1 \%$ horse serum and $100 \mathrm{ng} / \mathrm{ml} \mathrm{NGF}$ (Sigma). Images were captured using a microscope equipped with a digital camera (Olympus). For oligonucleotide treatment, the oligonucleotides $(2 \mu \mathrm{g} / \mathrm{ml}$, antisense: 5'-GGG GCA GCG GCC GTG GGC AT-3' or missense: 5'-GTG GCG CGG GCC GTA GGC AG-3') were added into the culture medium during PC12-cell-induced differentiation. A fresh medium with the same concentration of NGF and oilgonucleotides was used each day. For transient transfection, PC12 cells were seeded at a density of 3000 cells $/ \mathrm{cm}^{2}$ in a $35-\mathrm{mm}$ dish pre-coated with gelatin. The transfection was performed using the FuGene 6 reagent and the transfection efficiency was about $80 \%$.

\section{Neurite length measurement}

To measure neurite length, PC12 cells were induced to differentiate by NGF, and the images were captured randomly. The cells in the images were divided into eight groups, with 20 cells in each group. The total neurite length of each group was calculated by the Scion Image software (Scion Corporation, Frederick, MD, USA), and the average neurite length was calculated.

\section{Subcellular fractionation}

PC12 cells that stably express HA-rSac3 were cultured at $37^{\circ} \mathrm{C}$ with $5 \% \mathrm{CO}_{2}$. Cells were collected and homogenized thoroughly in buffer A (20 mM HEPES, pH 7.4, 1 mM EDTA, 255 mM sucrose). The subcellular fractions were separated as previously described [33]. In brief, the homogenate was centrifuged at $1000 \times g$ for $5 \mathrm{~min}$ to remove the cell debris, and then the supernatant was centrifuged at $19000 \times g$ for $20 \mathrm{~min}$. The resulting supernatant was centrifuged at $41000 \times g($ HITACHI CS150GX) for $20 \mathrm{~min}$, yielding a pellet designated as a high-density microsomal fraction (HDM). The supernatant was centrifuged again at $180000 \times g$ for $75 \mathrm{~min}$, by which stage the pellet could be designated as a low-density microsomal fraction (LDM). The pellet obtained from the initial spin was layered onto $1.12 \mathrm{M}$ sucrose in buffer A and centrifuged at $100000 \times \mathrm{g}$ in a Beckman SW-41 rotator (Beckman L-80 ultracentrifuge) for $60 \mathrm{~min}$. The white fluffy band at the interface was designated as the PM fraction, whereas the pellet was designated as the mitochondria/nuclei fraction $(\mathrm{M} / \mathrm{N})$. The PM fraction was diluted in buffer $\mathrm{A}$ and pelleted at $40000 \times g$ for $20 \mathrm{~min}$. All fractions were subjected to western blot analysis.

\section{Fluorescence microscopy}

Immunostaining was performed as previously described [34]. In brief, COS-7 cells were transiently transfected with HA-tagged rSac3 (0.4 $\mu \mathrm{g}$ DNA/35 mm dish) using the FuGene 6 and according to the manufacturer's instructions. After $20 \mathrm{~h}$, cells were fixed in $4 \%$ formaldehyde and permeabilized with CMA (chloroform:methanol: acetone in the ratio $1: 2: 1)$ at $-20^{\circ} \mathrm{C}$ for $30 \mathrm{~min}$. After being blocked at room temperature for $1 \mathrm{~h}$, cells were stained with various antibodies. These include the monoclonal antibodies against HA (1:500, Sigma), EEA1 (early endosomal antigen 1) (1:100, BD Bioscience, Franklin Lakes, NJ, USA), M6PR (mannose 6-phosphate receptor) (1:200, Abcam Ltd, Cambridge, UK) and MCFD2 (multiple coagulation factor deficiency protein 2) (1:150, [35]), and the polyclonal antibodies against HA (Y-11, 1:100, Santa Cruz Biotechnology, CA, USA), Rab11 (1:200, Zymed Laboratories, South San Francisco, CA) and Caveolin-1 (1:100, Santa Cruz, CA). FITC-and Cy3-conjugated secondary antibodies (1:500) were obtained from the Jackson ImmunoResearch Laboratories (West Grove, PA, USA). The dyes used for cell organelle staining were wheat germ agglutinin (WGA) (1:200, Sigma), ConA (1:200, Molecular Probes, Inc., Eugene, OR, USA), LysoTracker (1:200, Molecular Probes) and MitoTracker (1:5000, Molecular Probes). Fluorescence images were obtained by using confocal microscopy with a depth of field of 0.5-0.6 $\mu \mathrm{m}$ (TCS SP2, Leica, Heidelberg, Germany).

\section{Production of anti-rSac3 antibody}

The coding region of the Sac domain of rSac3 (amino acid 590907) was amplified by PCR and subcloned into the pQE31 vector (Qiagen). The His 6 -tagged fusion protein was expressed in Escherichia coli M15 (Qiagen) and purified using the Ni-NTA column 
according to the manufacturer's instructions. In brief, 11 of bacteria culture was grown at $37^{\circ} \mathrm{C}$ to an $\mathrm{OD}_{600}$ of 0.4 prior to induction with $0.1 \mathrm{mM}$ isopropylthio- $\beta$-D-thiogalactopyranoside (IPTG) for $3 \mathrm{~h}$ at $30^{\circ} \mathrm{C}$. Cells were pelleted and sonicated in $60 \mathrm{ml}$ lysis buffer $(50 \mathrm{mM}$ Tris-HCl, pH 8.5, $5 \mathrm{mM} \beta$-mercaptoethanol, $100 \mathrm{mM} \mathrm{KCl,} 1 \mathrm{mM}$ PMSF, $1 \mu \mathrm{g} / \mathrm{ml}$ leupeptin, $1 \%$ Triton X-100) on ice. The lysate was centrifuged at $18000 \times g$ for $15 \mathrm{~min}$ at $4{ }^{\circ} \mathrm{C}$. The supernatant was then incubated with a Ni-NTA resin for $2 \mathrm{~h}$ with gentle agitation at $4{ }^{\circ} \mathrm{C}$. Following incubation, the resin was poured into a column and washed with 10 resin volume of Tris buffer A ( $20 \mathrm{mM}$ Tris- $\mathrm{HCl}, \mathrm{pH}$ $8.5,500 \mathrm{mM} \mathrm{KCl}, 20 \mathrm{mM}$ imidazole, $5 \mathrm{mM}$ b-mercaptoethanol, $10 \%$ glycerol) and 5 resin volume of Tris buffer B $(20 \mathrm{mM}$ Tris- $\mathrm{HCl}, \mathrm{pH}$ 8.5, $1 \mathrm{M} \mathrm{KCl}, 5 \mathrm{mM} \beta$-mercaptoethanol, 10\% glycerol). The $\mathrm{His}_{6}-$ tagged fusion protein was eluted with 5 resin volume of Tris buffer C (20 mM Tris- $\mathrm{HCl}, \mathrm{pH} 8.5,100 \mathrm{mM} \mathrm{KCl,} 100 \mathrm{mM}$ imidazole, $5 \mathrm{mM} \beta$-mercaptoethanol, $10 \%$ glycerol). The elution product was dialyzed in PBS at $4{ }^{\circ} \mathrm{C}$ overnight and used to immunize two rabbits to generate anti-rSac3 antiserum.

\section{Expression of GST and rSac3 Sac domain fusion proteins}

The coding region of the Sac domain of rSac3 (amino acid 82-609) was amplified by PCR and subcloned into pGEX-4T-3 downstream of the coding sequence of glutathion $S$-transferase (GST). The fusion protein was expressed in E. coli BL21 CondonPlus (Stratagene). Protein expression was induced overnight at $16{ }^{\circ} \mathrm{C}$ by the addition of $0.1 \mathrm{mM}$ IPTG. The GST fusion protein was purified from bacterial lysate using the glutathione sepharose 4B resin (Amersham Pharmacia Biotech, Piscataway, NJ, USA), according to the manufacturer's instructions. In brief, bacteria from a 400-ml culture were disrupted through sonication in $40 \mathrm{ml} 50 \mathrm{mM}$ Tris- $\mathrm{HCl}(\mathrm{pH} 8.5), 100 \mathrm{mM} \mathrm{KCl}$, $5 \mathrm{mM} \beta$-mercaptoethanol, $1 \%$ Triton X-100 (v/v), $1 \mathrm{mg} / \mathrm{ml}$ leupeptin and $1 \mathrm{mM}$ PMSF. The lysate was centrifuged at $18000 \times g$ for 20 min to remove debris. GST-tagged proteins were then isolated from the soluble supernatant, extracted through the addition of $0.5 \mathrm{ml}$ equilibrated glutathione sepharose $4 \mathrm{~B}$ resin and incubated for $2 \mathrm{~h}$ at $4{ }^{\circ} \mathrm{C}$ with gentle agitation. Resins were then washed twice with the lysis buffer and three times with $50 \mathrm{mM}$ Tris- $\mathrm{HCl}$ (pH 7.2). The GST fusion protein bound to glutathione sepharose $4 \mathrm{~B}$ resin was then assayed for PIPPase activity.

\section{Site-directed mutagenesis}

Site-directed mutagenesis of $\mathrm{rSac} 3$ was conducted by PCR. The primers were: 5'-CCGGCATCCTTCGAACCAACTGCGTGGACTGTTTGGTTCGTACCA-3' and 5'-CGGAATTCCCAGAGATGAGGTTTCCC-3'. The underlined nucleotides indicate the change introduced for the point mutation. The PCR-derived 392-bp fragment was digested by Bst XI and NcoI, and then subcloned into rSac3 cDNA. The correctly mutagenized clone was confirmed by sequence analysis and the same region of rSac3 (amino acid 82-609) was subcloned again into pGEX-4T-3. The same procedure was use for the expression and purification of the site-directed mutagenic protein.

\section{Phosphoinositide phosphatase activity assay}

PI(3)P, PI(4)P, PI(5)P, PI(3,5) $\mathrm{P}_{2}, \mathrm{PI}(4,5) \mathrm{P}_{2}, \mathrm{PI}(3,4,5) \mathrm{P}_{3}$ and diC $_{18}-$ phosphatidylserine were all purchased from Sigma. The phosphatase activity assays were carried out with $5 \mu \mathrm{l}$ of the resin-bound GST-Sac domain fusion protein, or the resin-bound GST site-mutated Sac domain fusion protein, in a final volume of $50 \mu 150 \mathrm{mM}$ Tris- $\mathrm{HCl}$ (pH 7.2), $1 \mathrm{mM} \mathrm{MgCl}_{2}, 10 \mu \mathrm{g} / \mathrm{ml}$ porcine gelatin, $20 \mu \mathrm{M} \mathrm{diC}_{18}$-phos- phatidylserine. $20 \mu \mathrm{M}$ of each of $\mathrm{PI}(3) \mathrm{P}, \mathrm{PI}(4) \mathrm{P}, \mathrm{PI}(5) \mathrm{P}, \mathrm{PI}(3,5) \mathrm{P}_{2}$, $\mathrm{PI}(4,5) \mathrm{P}_{2}, \mathrm{PI}(3,4,5) \mathrm{P}_{3}$ was added as substrates. The mixture was further incubated at $37^{\circ} \mathrm{C}$ for $30 \mathrm{~min}$. Reactions were terminated by adding $50 \mu 1100 \mathrm{mM} \mathrm{N}$-ethylmaleimide (NEM) to the reaction mixture, followed by centrifugation at $18000 \times g$ at $4{ }^{\circ} \mathrm{C}$ for 15 $\min$. The released phosphate in the supernatant was quantified using the malachite green assay. To measure the kinetic properties of the recombinant GST-tagged Sac domain from rSac3, PI(3)P, PI(4)P or $\mathrm{PI}(3,5) \mathrm{P}_{2}(5-200 \mu \mathrm{M})$ was incubated with $3 \mathrm{mg}$ GST-Sac domain fusion protein at $37^{\circ} \mathrm{C}$ for $15 \mathrm{~min}$. The reaction product was measured using the malachite green method.

\section{Malachite green assay}

The malachite green assay was performed as previously described [36]. In brief, $50 \mu \mathrm{l}$ malachite green solution was added to $50 \mu \mathrm{l}$ supernatant, and the color was allowed to develop for $15 \mathrm{~min}$ at room temperature. Absorbance at $620 \mathrm{~nm}$ was measured, and the released phosphate was quantified by comparison with inorganic phosphate standards.

\section{Step-down inhibitory avoidance task}

The step-down inhibitory avoidance task was performed as described previously [31].

\section{Statistics}

Each experiment was repeated at least three times. Data shown are expressed as the mean \pm S.E.M. One-way ANOVA followed by Fisher LSD analyses were used to compare the effects of all treatments. The Statistica 6 software was used for statistical analysis.

\section{Results}

\section{Isolation and characterization of $r \mathrm{Sac} 3$}

To search for learning and memory-related functional genes, we utilized the step-down inhibitory avoidance task as a behavioral paradigm [31]. Hippocampal tissues from animals that did or did not receive step-down training were used to isolate RNA. For differential screening of an adult rat brain cDNA library, radioactive probes were generated from cDNA samples that were synthesized from RNA. Positive clones were analyzed, and the DNA sequences were used to search the GenBank to determine known or novel cDNA clones. A novel cDNA was identified and the full-length cDNA was obtained as described in the experimental procedures. This novel cDNA showed a high degree of sequence similarity to a human cDNA sequence, KIAA0274 (82.6\%). Sequence analysis indicates that this cDNA contains a 2724-bp open reading frame that is capable of encoding a protein of 907 amino acids with a relative molecular mass of $100 \mathrm{kDa}$ (Figure 1A). Since KIAA0274 was predicted as the human $\mathrm{Sac} 3$ gene (hSac3), we named this gene as rat Sac3 (rSac3, GenBank accession number: DQ666853). Rat genome sequence analysis showed that the rSac3 gene is localized at rat chromosome 20q12, and spans approximately $77 \mathrm{~kb}$ with 23 exons. The $\mathrm{N}$-terminal amino-acid sequence of rSac3 showed homology with the 
Sac domain, which was first found in Saccharomyces cerevisiae Sac1p [10]. The Sac domain of $\mathrm{rSac} 3$ contains seven conserved motifs, and shares identities with that of hSac3 (96.3\%), hSac1 (34.9\%), hSac2 (35.6\%), S. cerevisiae Sac1p (31.4\%), Fig4p (50.0\%), rat synaptojanin 1 (33.3\%) and rat synaptojanin $2(34.8 \%)$. The highly conservative catalytic sequence RTNCVDCLDRTN in the sixth motif of the Sac domain of rSac3 (Figure 1B) indicates that this protein might also have PIPPase activity. The C-terminal amino-acid sequence of $\mathrm{rSac} 3$ showed homology to $S$. cerevisiae Fig4 $\mathrm{p}$, suggesting that it might belong to the second subfamily of Sac domain proteins (Figure 1C).

Northern blot analysis showed that the $4.0-\mathrm{kb}$ rSac3 transcript exists in many tissues, including cortex, hippocampus, kidney, liver, lung, skeletal muscle, spleen and testis (Figure 2A). To examine the expression of the rSac3 protein, we generated a polyclonal antibody against the $\mathrm{C}$ - terminal portion of rSac3. This antibody was able to recognize a $110-\mathrm{kDa}$ band in COS-7 cells that overexpress rSac3 (data not shown). Consistent with northern blot analysis, the antibody could detect rSac3 protein in the spinal cord, cerebellum, cortex and hippocampus regions of the central nervous system, as well as in the kidney, liver, lung and testis (Figure 2B).

\section{rSac3 is localized to the ER, Golgi complex and recycling endosomes}

Since the anti-rSac3 antibody that we produced was not suitable for immunostaining, in order to determine the subcellular localization of $\mathrm{rSac} 3$ protein we transfected the HA-rSac3 expression vector into COS-7 cells, and analyzed its distribution by using markers associated with different subcellular compartments. Double staining showed that the rSac3 protein was mainly localized in the cytoplasm, with

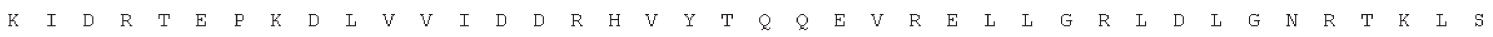
241 CAGAAAGGATCCTCCGGGTTGTTTCGAGCCGTCTCCGCGTTTGGTGTCGTAGGTTTTGTCAGGTTCTTAGAAGGCTACTATATCGTATTAATAACTAAGCGGAGGAAGATGGCGGATATC

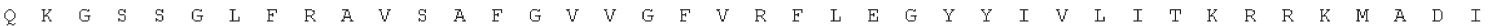

361 GGAGGCCATGCAATATATAAGATTGAAGATACAAGTATGATTTATATCCCCAATGACTCTGTTCGGATTACTCACCCCGACGAAGCTAGGTACCTAAGGATATTCCAAAATGTGGATCTG

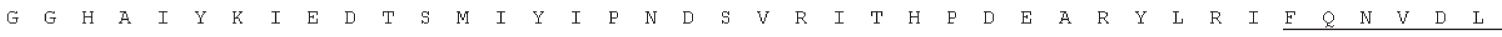

481 TCCAGCAATTTTTACTTTAGTTACAGCTATGATCTGTCCCACTCCCTTCAGTACAATCTTACCGTCCTGCGAATGCCCCTGGAGATGTTAAAGTCGGAAACATCCAAGACCTGCCAGGAG

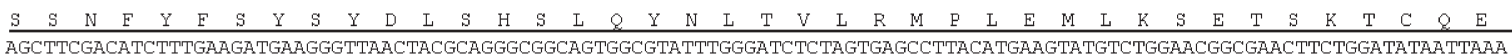

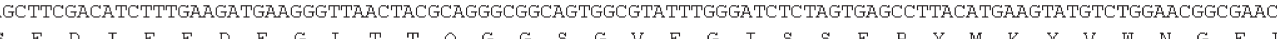

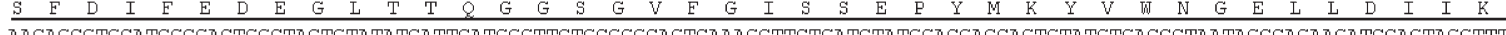

721 AACAGCGTGCATCGCGACTGGCTACTGTATATCATTCATGGGTTCTGCGGGCAGTCAAAGCTTCTGATCTATGGACGACCAGTGTATGTGACCCTAATAGCCAGAAGATCCAGTAGGTTT

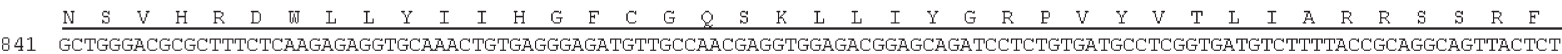

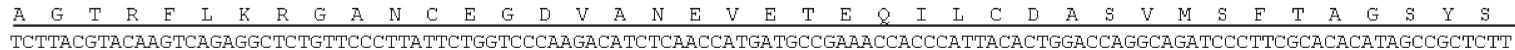

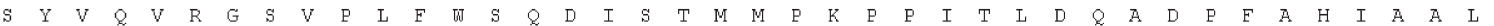

1081 CACTTTGACCAGATGCTGCAGAGGTTTGGCTCCCCCATCATCATCCTGAACTTAGTGAAGGAGAGAGAGAAGAGAAAGCACGAAAGGATTCTGAGCGAGGAGCTGGTGGCCGCGGTTACT

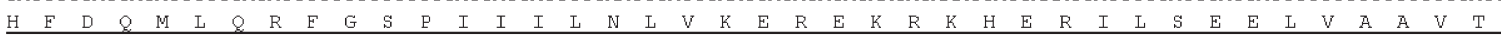

1201 TACCTTAACCAGTTCCTGCCCCCGGAGCACAGCATTGTATACATTCCCTGGGATATGGCCAAGTACACCAAGAGTAAGCTGTGTAACGTTCTCGATCGTCTGAACGTGATTGCAGAAAGC

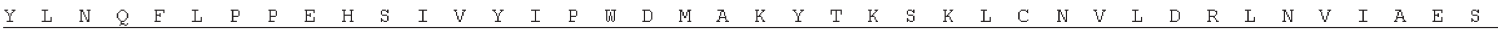

1321 GTGGTAAAGAAGACAGGCTTCTTCGTCAACCGCCCTGATTCTTACTGCAGCGTTTTACGGCCAGATGAGAAGTGGAACGAACTAGGAGGTCGTGTGATTCCCACTGGTCGGCTCCAGACC

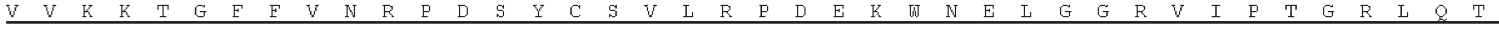

1441 GGCATCCTTCGAACCAACTGCGTGGACTGTTTGGATCGTACCAACACGGCGCAGTTCATGGTGGGCAAGTGCGCCCTGGCTTACCAGCTGTACTCCTTAGGGCTGATTGACAAGCCCAAC

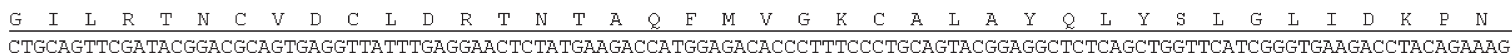
1561 CTGCAGTTCGATACGGACGCAGTGAGGTTATTTGAGGAACTCTATGAAGACCATGGAGACACCCTTTCCCTGCAGTACGGAGGCTCTCAGCTGGTTCATCGGGTGAAGACCTACAGAAAG

1681 ATAGCGCCGTGGACCCAGCACTCCAAGGACATCATGCAGACGCTGTCTCGGTACTACAGCAATGCCTTTTCAGATGCGGACAGACAAGATTCCATCAACCTGTTCTTGGGTGTTTTCCAC

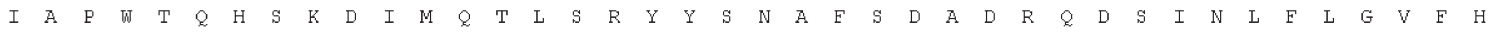

1801 CCCACAGAAGGGAAACCTCATCTCTGGGAACTTCCCACGGACTTTTACCTGCATCACAAAAACACCATGAGCCTTTTACCCCCCAAAAGGAGTTATACTCACTGGTGGACACCAGAGGTG

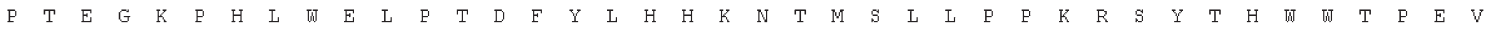

1921 GTGA.GCATTTGCCGCTGCCTTACGACGAAGTTATCTGTGCTGCAAACTTAAAGAAGTTGACGGTGAAGAAGTTTCACAGATGGGAAGAGGAGATTGATATTCACAATGAGTTCTTCCGG

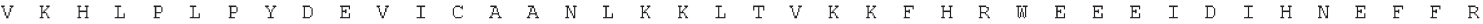

2041 CCGTATGA.TTGAGTAGTTTGATGACACCTTTTGCCTGGCCATGACAAGTTCAGCACGTGATTTTATGCCTAAAACTATTGGCATTGACCCAAGTCCATTCACCGTGCGAAAACCAGAC

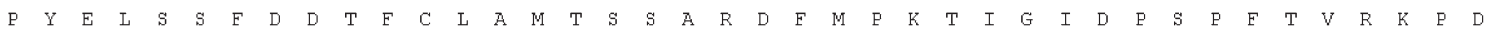

2161 GAAACCGGGAAATCTGTACTGGGGAACAAAAGCAACAGAGAGGAGGCCGTCCTGCAACGGAAAACGGCAGCCAGCGCCCCGCCACCCCCCAGCGAGGAGGCCGTGTCCAGCAGCTCCGAG

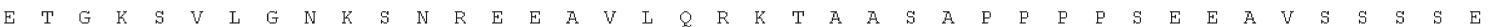

2281 GACGACTCTGGTACTGACCGGGAAGACGAAGGTTCCATCTCGCAGCGATCCACTCCTGTGAAGATGACTGACACCGGAGACAGCGCCAAAGTGACTGAGAGTGTGGCCCAACCCATGAAG

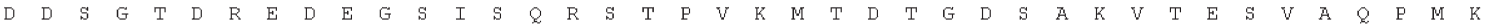

2401 GAAGTGTACGGAGTTAGCCTCTCACGTAGCCTGTCCGAGGAGGATCACTCCATTTATGCCAGGTTTGTTCAACTGGGGCAGAGTCAGCATAGACAGGACTGGAGCAGCCCGCAGATGTGT

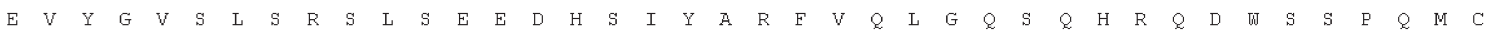

2521 GCCCGGTGCTCAGACGGAGTTATCAAACTAACCCCCATCTCAGCTTTCTCGCAAGACAACATTTATGAAGTTCAGCCCCCGAGAGTAGACAGAAAGTCCACAGAGATCTTCCAGGCCCAC

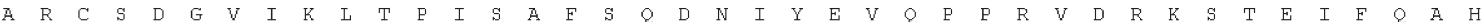

2641 ATCCAGGCCAGCCAAGGTATCATGCAGCCCCTTGGCAAAGAGGACACTGCCATATACCGGGAGTACATCAGAAACCGCTACTTATAACGACGGCCCCGAGGACAGTGGGGTTAGCTTCTT

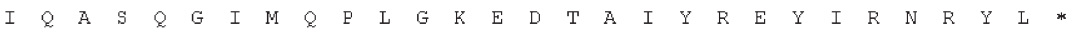

2761 TTCAGTGTTGTCTGCGAGAAGGAATTCCCAGGACCTGGAGATGCAGCTCAGTAGTAAAGGACACGTACTTCCAGAGGCTCGGAACCTGGTCCCCAGCACCCGTATCACAACCTTCGGTAA 2881 CTCCAGCTACAAAGAATCCAATGTTGTCTTCTGTATTTTGTACACACCTATACTCAAGTGGGTGCCTGTGTGTGTACACCCATGCACAGGCGAACATGCATATGCGTGCACATGCTTGCA

3001 CACACACACACACACACACTAAAAATACTAGAAGTGAAATCCTTAATAACCAATTCATCCAAATCATGGATCTGAAGCTTTTCACCCCTTTGAACCATGCAAATTACTAACTACAGGTAA

3121 TAAAGAAGTGTCTGCCTCTGAAAAAAAAAAAAAAAAAAAAAAAAAAAAAAAAAAAAAAAAA 
B

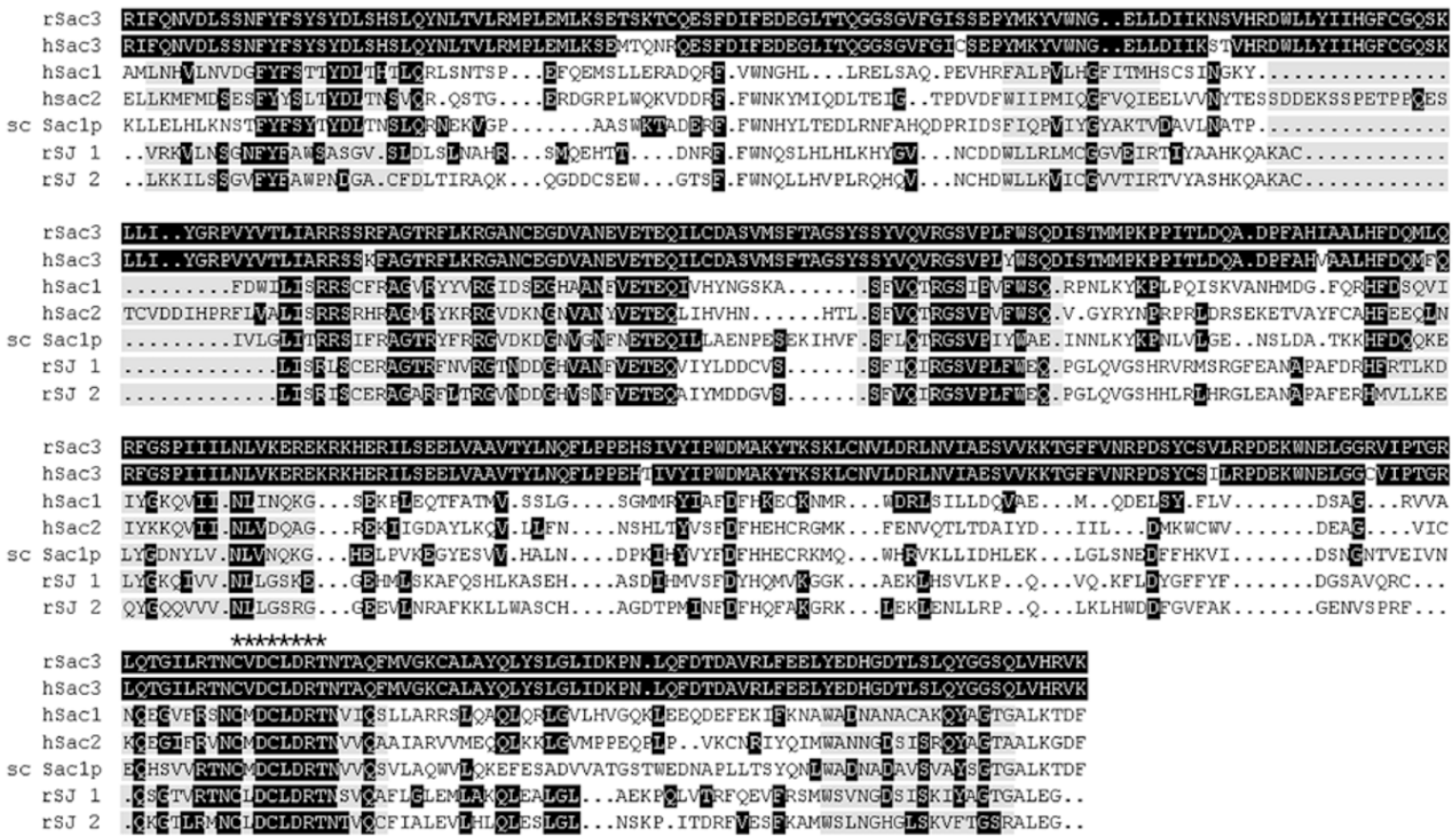

C

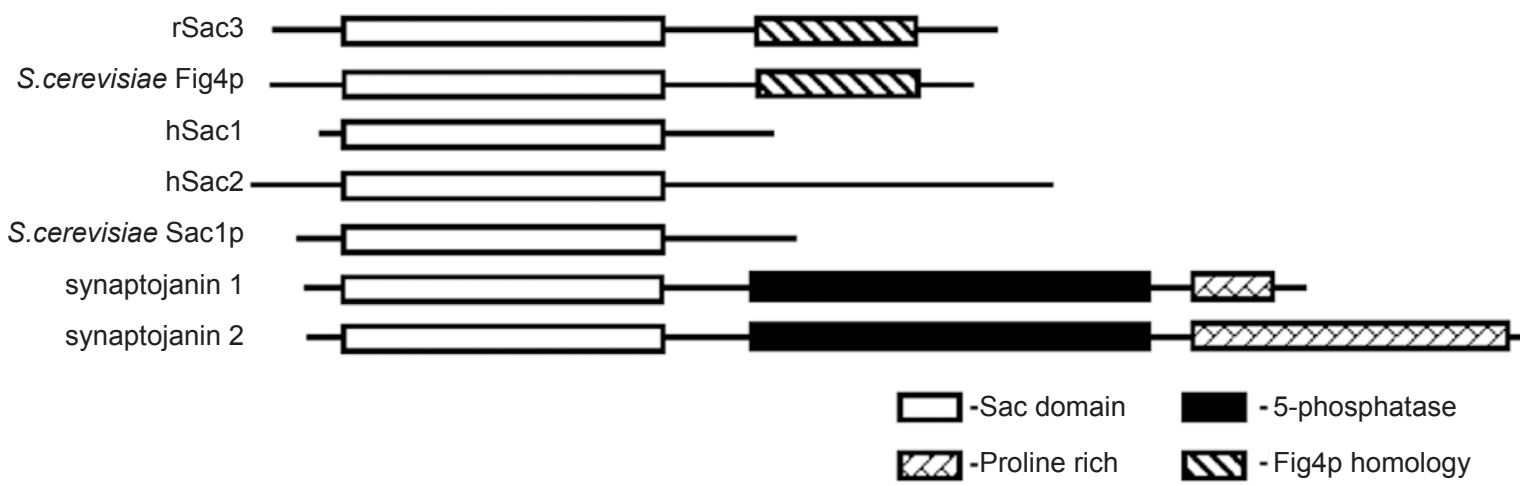

Figure $1 \mathrm{Sac} 3$ as a highly conserved gene with amino-acid sequence motifs of Sac and other domains. (A) Nucleotides and the corresponding amino-acid sequence of rat Sac3 (rSac3) cDNA. The amino-acid sequence of the Sac domain is underlined. (B) An amino-acid sequence comparison of $\mathrm{rSac} 3$ and other family members. Highlighted amino-acid residues indicate highly conserved residues among the entire group and identity between rat and human Sac3. An analysis of the overall homology organization also indicates seven motif blocks; these are shaded in gray. The conserved $\mathrm{CX}_{5} \mathrm{R}(\mathrm{T} / \mathrm{S})$ in motif $\# 6$ commences at the rSac3 residue 486 , and is highlighted by asterisks above the sequence. (C) A diagramatic presentation of the homology domains in Sac-domain-containing proteins. The Sac domain (open box) is shared among all members of the group near their N-terminus. Synaptojanin 1 and synaptojanin 2 have a type II 5-phosphatase catalytic domain (filled box) and a proline-rich region (hatched box) near the C terminus of the protein. The striped box marks a homology domain between rSac3 and yeast Fig4p. Abbreviations: rSac3, rat Sac3; hSac1, hSac2, hSac3, human Sac1, Sac2, Sac3; sc Sac1p, Saccharomyces cerevisiae Sac1p; rSJ1, rSJ2, rat synaptojanin 1 and 2.

a high to low gradient from the perinuclear to the region near the PM. No detectable signal could be observed in the nuclear and PM (Figure $3 \mathrm{~A}$ a, e, i, m). It also showed that there was a colocalization of $\mathrm{rSac} 3$ with concanavalin $\mathrm{A}$ (ConA), an ER marker (Figure 3A a-d) [37], MCFD2, the ER-Golgi intermediate compartment marker (Figure 3A e-h) [35], WGA, a Golgi complex marker (Figure 3A i-l) [38] and Rab11, a trans-Golgi network and recycling endosome marker (Figure 3A m-p) [39, 40]. No colocalization of rSac3 with the early endosome marker early endosomal antigen 1 (Supplementary information Figure S1D-F) [41], the late endosome marker mannose 6-phosphate receptor 
A

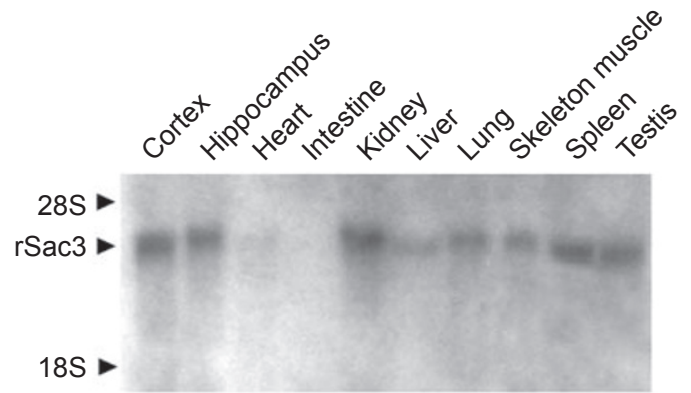

$18 \mathrm{~S}$

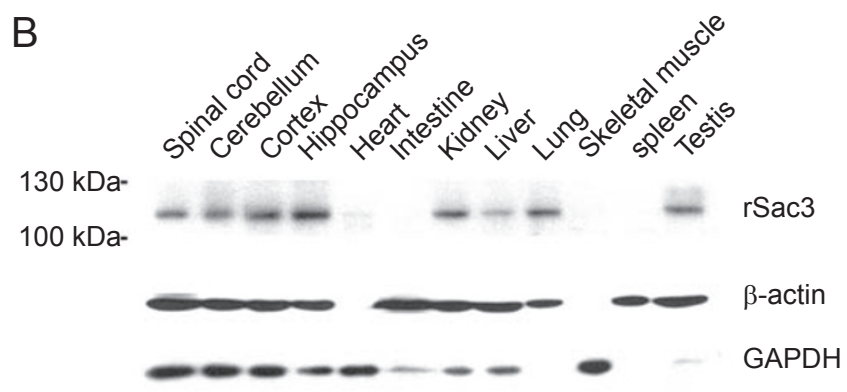

Figure 2 Expression pattern of rSac3. (A) A northern blot analysis of rSac3 mRNA in various tissues. $\mathrm{rSac} 3$ is widely expressed in different tissues, with a major transcript at $4 \mathrm{~kb}$. (B) Western blot analysis showed that the $\mathrm{rSac} 3$ protein is present in the spinal cord, cerebellum, cortex and hippocampus, as well as in the kidney, liver, lung and testis. Since heart and skeletal muscle did not express $\beta$ actin, we used GAPDH as another loading control.

(Supplementary information Figure S1G-I) [7] or the lipid fraft marker caveolin-1 [42] could be detected. We also used different subcellular compartment markers, such as the mitochondria marker MitoTracker [43] and the lysosome marker LysoTracker [44], to determine the subcellular localization of rSac3, but could not detect any double-positive signal. Similar results were obtained by transfecting EGFP-tagged rSac3 into COS-7 cells (data not shown).

To further confirm the subcellular localization of rSac3, we separated the different subcellular compartments of rSac3 stably tranfected PC12 cells by ultracentrifugation, and subjected the different fractions to western blot analysis. The $\mathrm{rSac} 3$ protein was concentrated in the LDM fraction, which contained the ER, Golgi complex and intracellular trafficking vesicles. A small amount of rSac3 protein could be detected in the HDM fraction. No positive signal could be found in the cytosol, $\mathrm{PM}$ and $\mathrm{M} / \mathrm{N}$ fractions (Figure 3B, upper panel). Consistent with immunostaining data, Rab11 also co-existed with rSac3 in the LDM fraction but it was also present in the HDM, M/N and cytosol fractions (Figure 3B, lower panel).
Taken together, these results show that the rSac3 protein mainly localizes in the ER, ER-Golgi intermediate compartments, Golgi complex and recycling endosomes, suggesting that this protein spans from the ER and Golgi complex, through the trans-Golgi network, to the intracellular vesicular trafficking compartments, and may play crucial roles in vesicular trafficking from the ER and Golgi complex to the PM.

\section{The Sac domain of rSac3 displays PIPPase activity}

To test the intrinsic PIPPase activity of rSac3, we expressed a fusion protein of GST and the Sac domain of rSac3 (amino acid 82-609), and measured the PIPPase activity of this fusion protein with in vitro assays. The Sac domain of rSac3 exhibited PIPPase activity when PI(3)P, PI(4)P and $\mathrm{PI}(3,5) \mathrm{P}_{2}$ were used as substrates, whereas $\mathrm{PI}(5) \mathrm{P}, \mathrm{PI}(4,5) \mathrm{P}_{2}$ and $\mathrm{PI}(3,4,5) \mathrm{P}_{3}$ were not suitable substrates for this protein (Figure 4A). To further analyze the kinetic properties of the Sac domain of rSac3, we determined the apparent $\mathrm{Km}$ values of PIPPase using Lineweaver-Burk plot analysis, and found that the $\mathrm{Km}$ values of the rSac3 Sac domain for PI(3)P, PI(4)P and $\mathrm{PI}(3,5) \mathrm{P}_{2}$ were comparable with other Sac-domain-containing proteins (Figure 4B) [24]. The sequence of RXNCV(L)DCLDRTN within the sixth motif of the Sac domain represents the catalytic core of the Sac PIPPase [10], and previous studies of this region have revealed that mutations in this region could block its enzymatic activity [23]. To confirm the importance of this sequence in the enzymatic activity of the Sac domain in $\mathrm{rSac} 3$, we introduced a point mutation, $\mathrm{D} 491 \mathrm{~V}$, into this sequence. When PIPPase activity was assayed, the phosphatase activity of the mutant protein, rSac3-D491V, was barely detectable with all phosphoinositides acting as substrates (Figure 4A). These results show that the Sac domain of rSac3 has intrinsic PIPPase activity, and the catalytic core of the phosphatase activity localizes in the sequence RXNCV(L)DCLDRTN, within the sixth motif of the Sac domain.

Overexpression of $r \mathrm{Sac} 3$ promotes neurite outgrowth in NGF-stimulated PC12 cells

To explore the potential involvement of $\mathrm{rSac} 3$ in neuronal function and the central nervous system, we used the NGF-stimulated PC12 cell neuronal differentiation as an in vitro cellular system. Western blot analysis showed that the expression level of rSac3 was increased along with the neuronal differentiation of $\mathrm{PC} 12$ cells (Figure 5A, F(5,30) $=3.904, p=0.0076)$. The upregulation of rSac3 started at day 2 (D2) after NGF stimulation, and it coincided with the neurite outgrowth of PC12 cells, suggesting that rSac3 may play a role in this process. To further explore this possibility, we established PC12 cell lines that were stably 
A
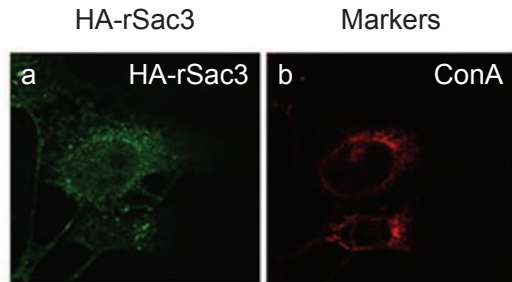

Overlay

$\mathrm{HM}$
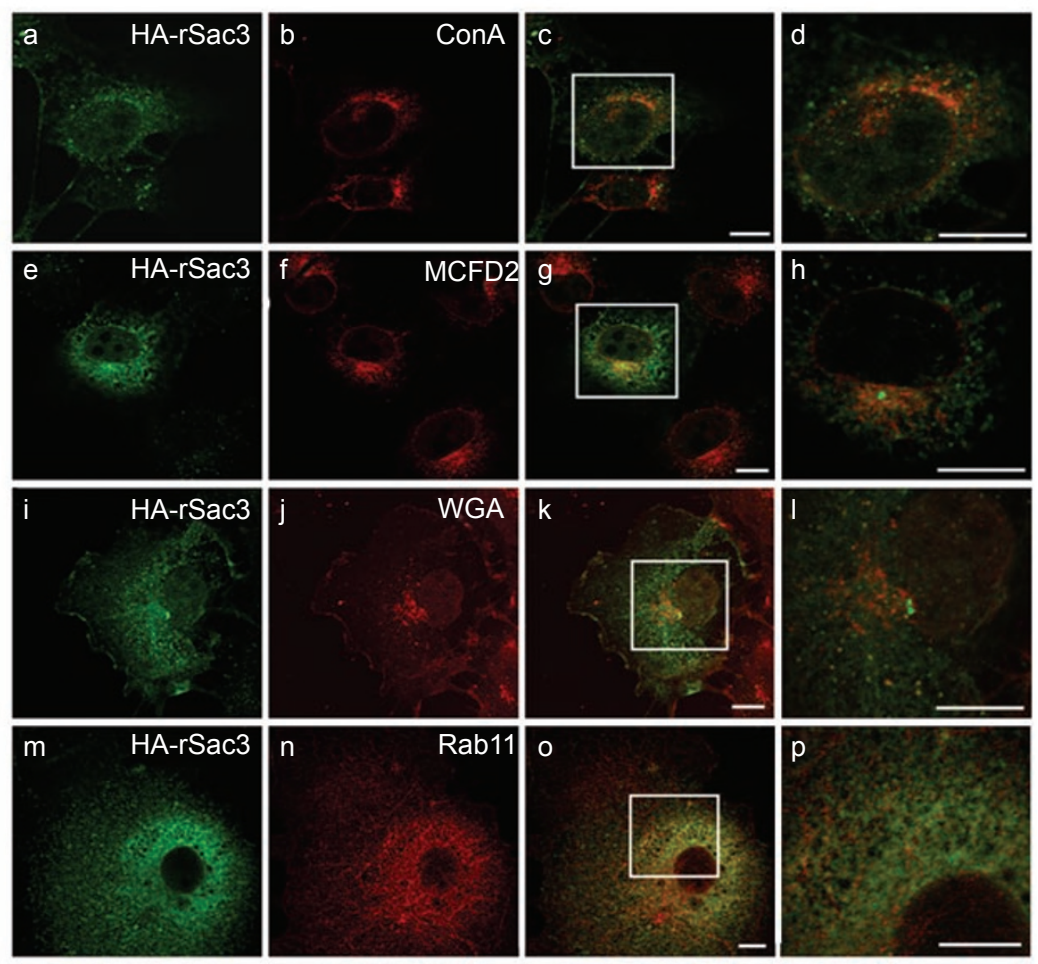

B

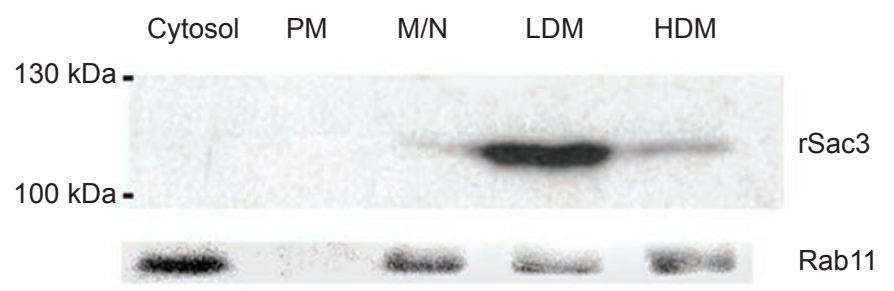

Figure 3 Subcellular localization of rSac3. (A) COS-7 cells were transfected with HA-rSac3 for 20 h, and were double stained with anti-HA antibody (a, e, i, m) together with specific dyes for ConA (b) and WGA (j), or with antibodies against MCFD2 (f) and Rab11 (n). Fluorescence images were obtained by confocal microscopy, and were merged to visualize colocalization (c, g, k, o), high magnification (HM) images were also shown $(\mathrm{d}, \mathrm{h}, 1, \mathrm{p})$. The scale bar indicates $10 \mu \mathrm{m}$. (B) PC12 cells that were stably transfected with HA-rSac3 were homogenized and fractionated according to the experimental procedure. The fractions were subjected to western blot analysis using anti-rSac3 (upper panel) or anti-Rab11 (bottom panel) antibodies.

transfected with rSac3 cDNA or control plasmid. From these cell lines, we randomly picked up two lines from each plasmid transfection (rSac3-PC12-1C and rSac3-PC12-2A versus HA-PC12-1A and HA-PC12-2D) for further study. We found no difference in the cell morphology or the rate of proliferation when comparing rSac3-transfected PC12 cells with normal or control-plasmid-transfected PC12 cells (data not shown). When these cells were stimulated with NGF to start neuronal differentiation, we observed that the neurite outgrowth of rSac3-PC12 cells was more robust than that of normal and control cells at day 3 (D3) and day 5 (D5) of NGF stimulation (Figure 5B). The neurite length measurement showed that the neurite outgrowth of rSac3-PC12 cells was significantly more extensive than that of normal and control PC12 cells starting from D2 of NGF stimulation (Figure 5C). Together, these results show that the rSac3 protein is upregulated in PC12 cells upon NGF stimulation, and that overexpression of $\mathrm{rSac} 3$ in $\mathrm{PC} 12$ cells promotes neurite outgrowth during NGF-stimulated neuronal differentiation.

Inhibition of $r \mathrm{Sac} 3$ expression results in reduced neurite outgrowth of NGF-stimulated PC12 cells

Since overexpression of $\mathrm{rSac} 3$ could promote neurite 


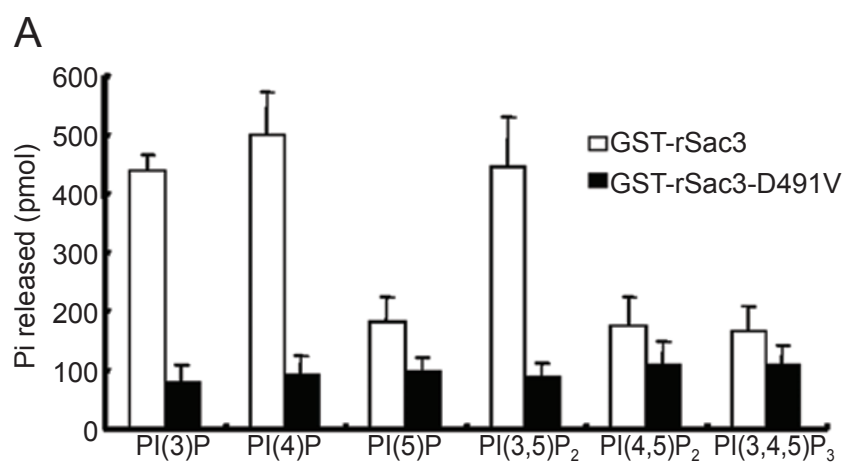

B
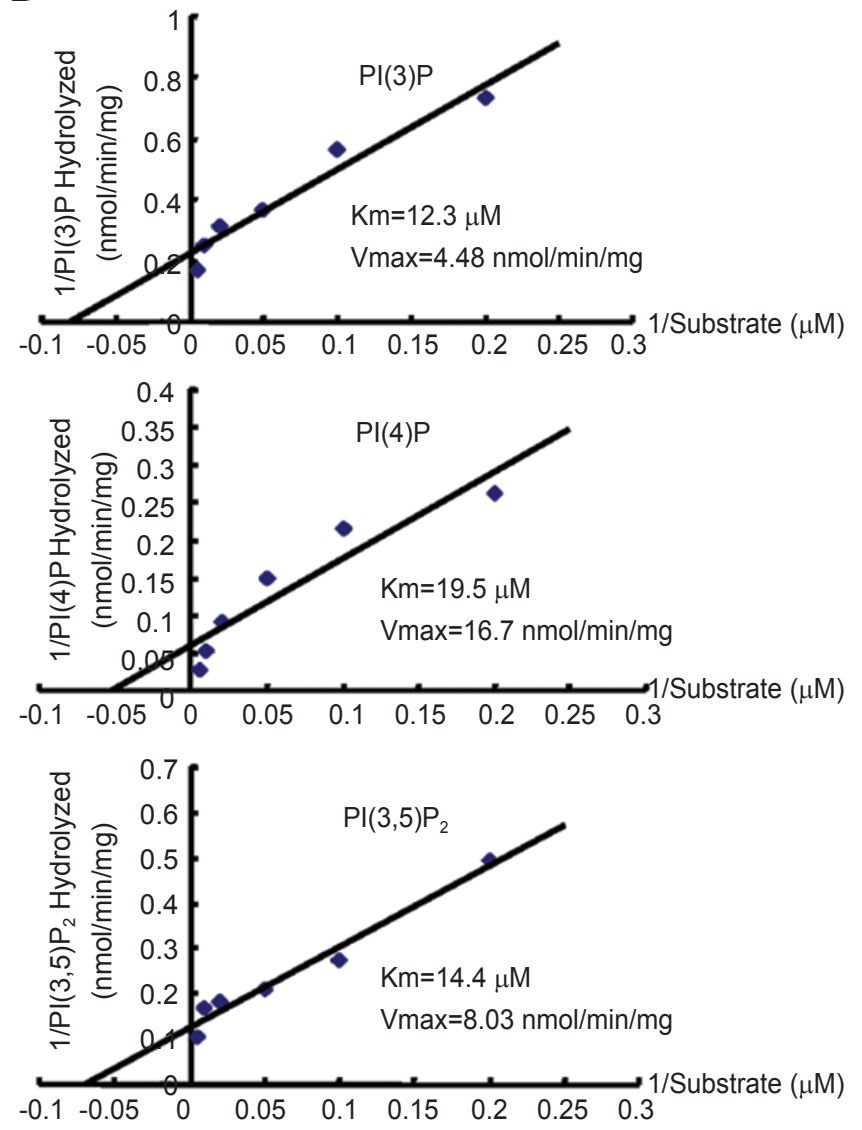

Figure 4 Enzymatic properties of the rSac3 Sac domain. (A) A profile of PIPPase activity in vitro for the Sac domain of rSac3. Recombinant GST-tagged Sac domains of the native and site-directed mutagenic forms were analyzed. Various phosphoinositide phosphate substrates were incubated with either the native or the D491V mutant Sac domain fusion protein at $37{ }^{\circ} \mathrm{C}$ for $30 \mathrm{~min}$. The released phosphates were measured using the malachite green method. The results were from six independent experiments (mean \pm S.E.M.). (B) The kinetic properties of the recombinant GST Sac domain fusion protein. PI(3)P, $\mathrm{PI}(4) \mathrm{P}$ or $\mathrm{PI}(3,5) \mathrm{P}_{2}(5-200 \mathrm{mM})$ was incubated with the GST Sac domain fusion protein at $37{ }^{\circ} \mathrm{C}$ for $15 \mathrm{~min}$. The reaction product was measured using the malachite green method. $\mathrm{Km}$ values were calculated using the Lineweaver-Burk analysis. Similar results were obtained from two independent experiments, and representative data are shown. outgrowth of NGF-stimulated PC12 cells, we examined whether the inhibition of rSac3 expression could impair the neurite outgrowth of PC12 cells. Using normal PC12 cells that were stimulated with NGF, we added an antisense oligonucleotide against $r S a c 3$ into culture medium to inhibit its expression, while using a missense oligonucleotide as a control. The neurite length of cells treated with antisense oligonucleotide was much shorter than the length of cells treated with missense oligonucleotide or normal PC12 cells at D3 and D4 of NGF stimulation (Figure 6A). The neurite outgrowth of PC12 cells treated with antisense oligonucleotide showed an approximately $20 \%$ decrease compared with the missense or normal groups (Figure 6B). Western blot analysis was used to confirm the inhibition of rSac 3 expression by antisense oligonucleotide, and the results showed that the protein level of rSac 3 was indeed suppressed in cells treated with antisense oligonucleotide, but not in cells treated with missense oligonucleotide or normal PC12 cells at D3 and D4 of PC12 cell neuronal differentiation (Figure 6C). These results show that the suppression of $\mathrm{rSac} 3$ by antisense oligonucelotide inhibits the neurite outgrowth of NGF-stimulated PC12 cells.

Site-specific mutation in the catalytic sequence of $r \mathrm{Sac} 3$ abolishes its neurite outgrowth promoting activity

Our above data have shown that rSac3 had PIPPase activity and could promote the neurite outgrowth of NGFstimulated PC12 cells. We wondered whether these two functional activities had a direct link. To address this question, we transiently transfected PC12 cells with cDNA coding for wild-type rSac3 (HA-rSac3) or a mutant harboring a mutation in the catalytic sequence of rSac3 (HA-rSac3D491V), and stimulated these cells with NGF for neuronal differentiation. Cells transfected with the vector plasmid (HA-pcDNA3-PC12) were used as the control. As shown in Figure 6D, the neurite length of rSac3-transfected cells was significantly longer than that of vector-transfected and normal PC12 cells. Cells that were transfected with the rSac3 mutant, however, showed no neurite-outgrowth-promoting activity. Stably transfected cells also showed similar results (data not shown). These results link the PIPPase activity of rSac3 with its function in promoting neurite outgrowth, suggesting that this protein plays crucial roles in the neurite outgrowth of NGF-stimulated PC12 cells.

\section{Discussion}

Sac-domain-containing proteins constitute a newly identified family of proteins that share the property of PIPPase. What are the biological functions of such Sac domain proteins? To address this question, we utilized the rSac3 that we identified in a behavioral screening of a rat 
A

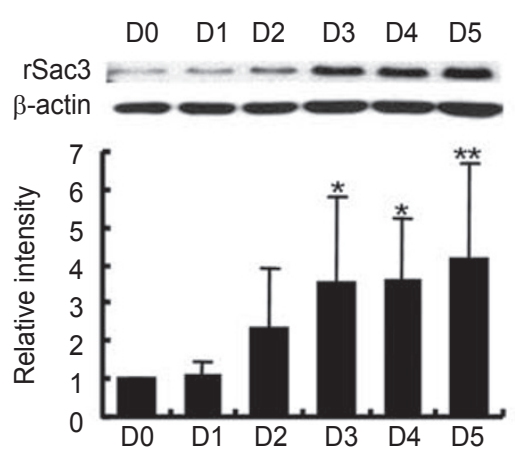

B

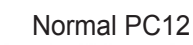

D1

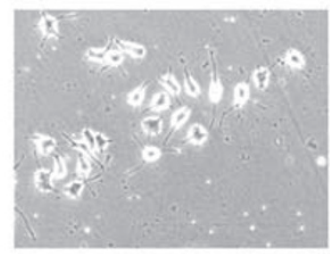

D3
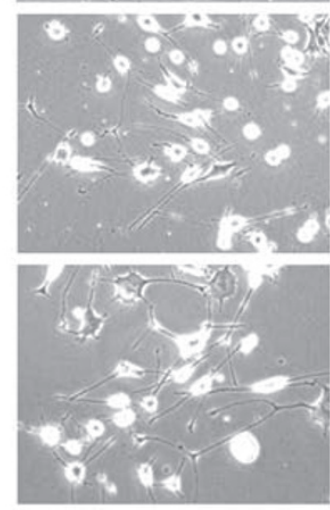

HA-pcDNA3-PC12
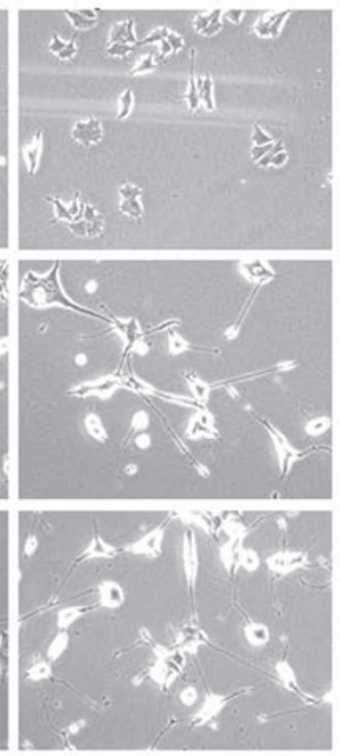

HA-rSac3 PC12
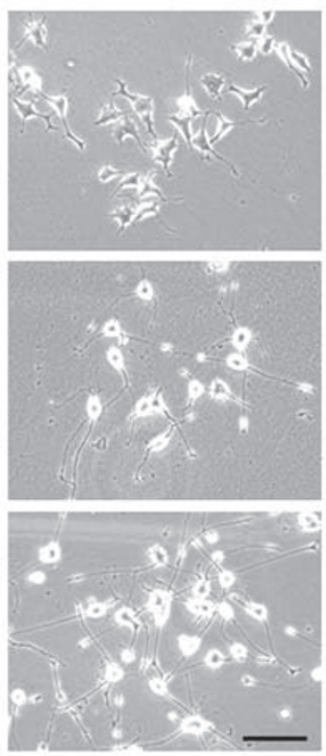

C

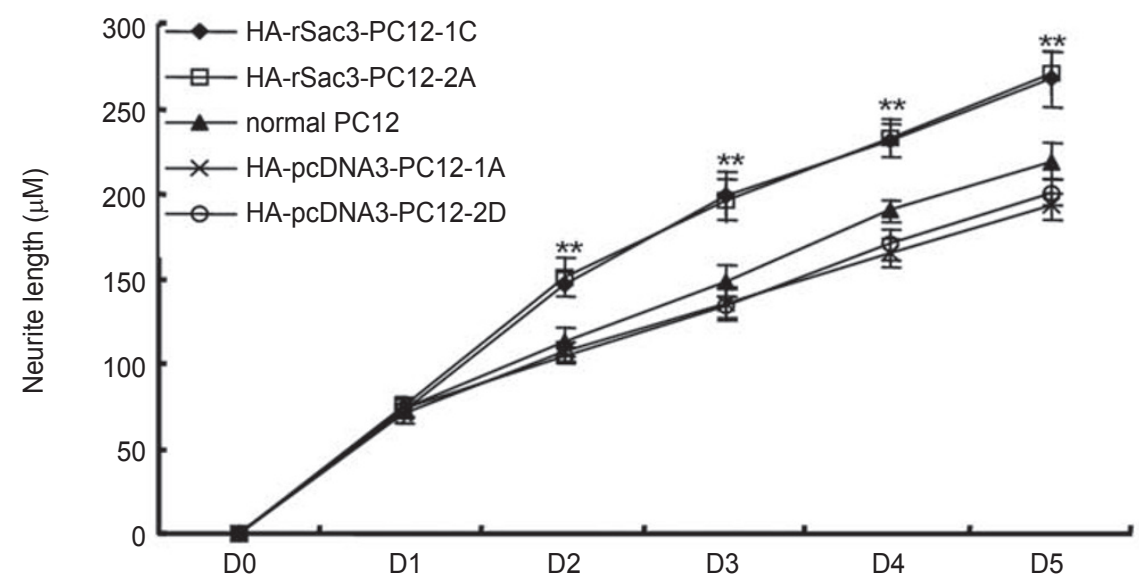

Figure 5 rSac3 promotes neurite outgrowth in NGF-stimulated PC12 cells. (A) Elevated expression of rSac3 in PC12 cells after treatment with NGF is shown. Upper panel: PC12 cells were induced to differentiation with NGF and cells were harvested at various times after treatment with NGF. Cell lysates were used for western blot analysis with anti-rSac3 antibody. Bottom panel: rSac3 protein levels relative to day 0 (D0) levels were calculated and data were shown as the mean \pm S.E.M. $(n=6)$. ${ }^{* *}$ There was a significant difference of $\mathrm{rSac} 3$ expression level from different days after NGF stimulation: $\mathrm{F}(5,30)=3.904, p=0.0076 ; * p<0.05$ from day 3 (D3) and day 4 (D4) versus day 0 (D0); ** $<0.01$ from day 5 (D5) versus day 0 (D0), one-way ANOVA, followed by Fisher LSD analysis. (B) Normal PC12 cells and those stably transfected with either HA-rSac3 or a vector plasmid control (HA-pcDNA3) were cultured as described in the experimental procedure. Images were taken at days 1, 3 and 5 after NGF stimulation. (C) Neurite length was measured using the Scion Image software. Data are shown as the mean \pm S.E.M. $(n=160)$. The neurite outgrowth of rSac3-PC12 cells was significantly more extensive than that of normal and control PC12 cells that were started at day 2 after NGF stimulation. $\mathrm{D} 1: \mathrm{F}(4,35)=0.459, p=0.765 ; \mathrm{D} 2: \mathrm{F}(4,35)=68.82, p<0.01 ; \mathrm{D} 3: \mathrm{F}(4,35)=64.33, p<0.01 ; \mathrm{D} 4: \mathrm{F}(4,35)=108.07, p<0.01 ; \mathrm{D} 5$ : $\mathrm{F}(4,35)=83.32, p<0.01 ;{ }^{*} p<0.01$ for HA-rSac3-PC12 cells versus normal PC12 or HA-pcDNA3-PC12 cells, one-way ANOVA, followed by Fisher LSD analysis. The scale bar indicates $100 \mu \mathrm{m}$. 
A

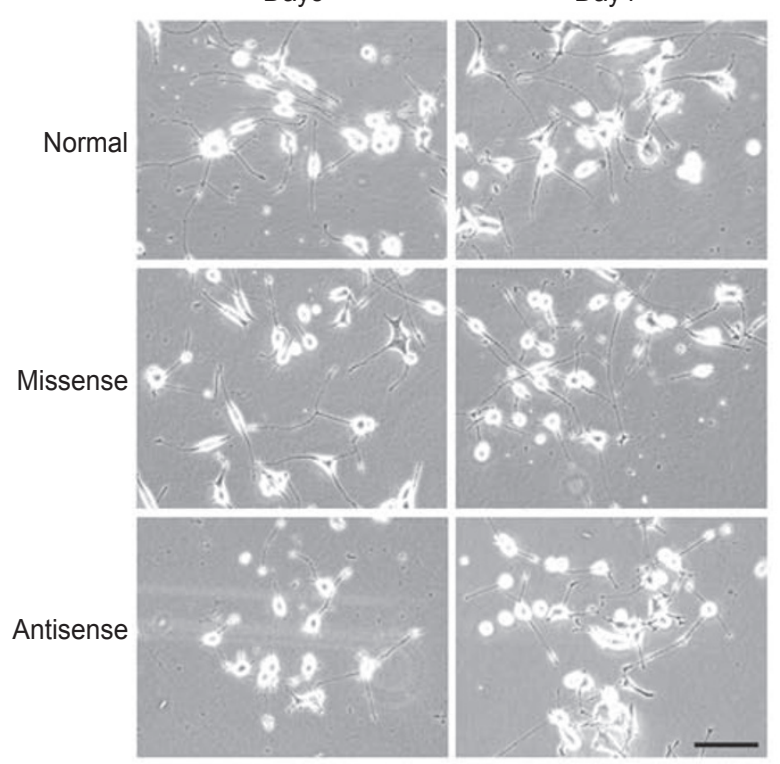

C
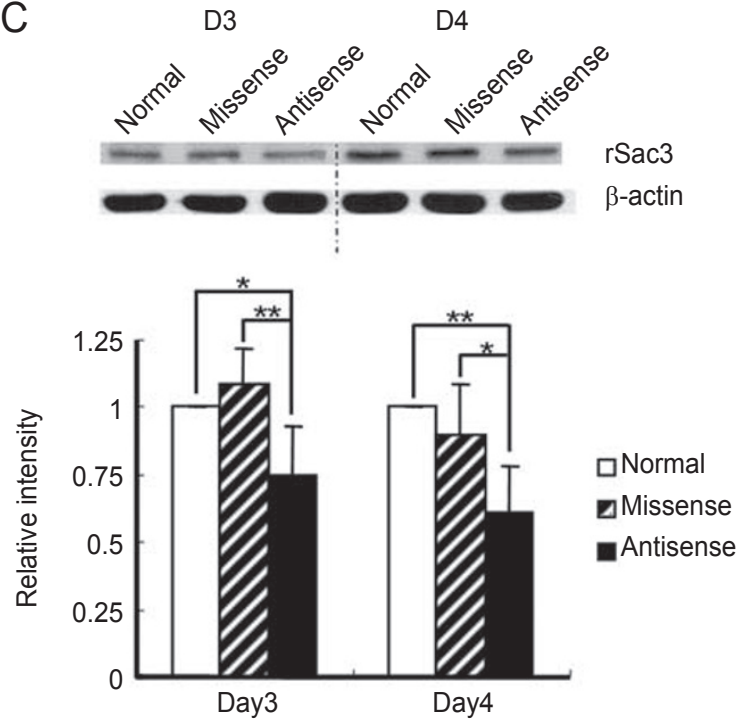

B

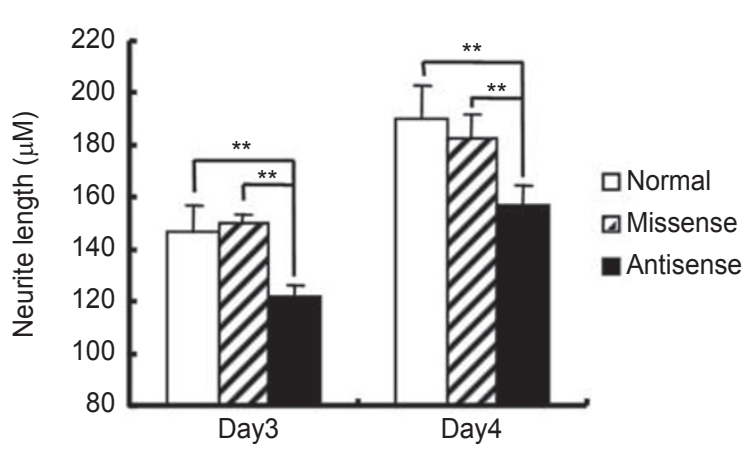

$\mathrm{D}$

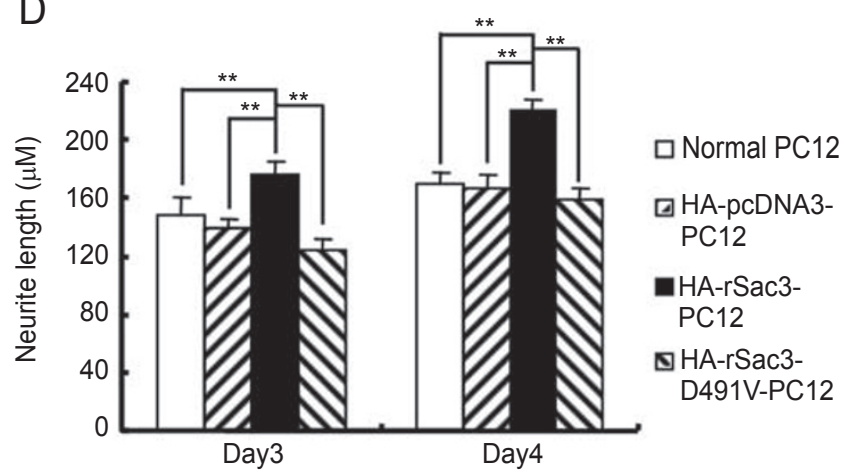

Figure 6 Enhanced neurite outgrowth by rSac3 was abolished by either inhibition of rSac3 expression or mutation in the catalytic core of the Sac domain. (A) PC12 cells were treated with either anti-rSac3 antisense oligonucleotides or missense oligonucleotides (as a control) from day 0. Images were taken at days 3 and 4 after NGF stimulation. (B) The neurite length of PC12 cells that were treated with rSac3 antisense oligonucleotides was significantly decreased compared with missense and normal groups $(\mathrm{n}=160)$. Data are shown as the mean \pm S.E.M. D3: $\mathrm{F}(2,21)=38.93, p<0.01$; $\mathrm{D} 4: \mathrm{F}(2,21)=23.26, p<0.01 ; * * p<0.01$ for the antisense group versus the control groups (normal or missense group, one-way ANOVA, followed by Fisher LSD analysis). (C) Western blot analysis showed that the rSac3 protein level was decreased by antisense oligonucleotides. Bottom panel: the protein level of rSac 3 from the antisense group or missense group relative to that of the normal group at day 3 and day 4 . Data are shown as the mean \pm S.E.M. $*$ Significantly different from normal, missense and antisense groups $(\mathrm{D} 3: \mathrm{F}(2,9)=7.45, p=0.012$; $\mathrm{D} 4: \mathrm{F}(2,9)=7.72, p=0.011)$. * $p<0.05$ for the antisense group versus the normal group at day 3 and versus the missense group at day $4 ; * * p<0.01$ for the antisense group versus the missense group at day 3 and versus the normal group at day $4(n=4$, one-way ANOVA, followed by Fisher LSD analysis). (D) PC12 cells were transiently transfected with various plasmids and were treated with NGF to induce neuronal differentiation. Neurite length was measured as described. Data are shown as the mean \pm S.E.M. D3: $\mathrm{F}(3,28)=43.01, p<0.01 ; \mathrm{D} 4: \mathrm{F}(3,28)=83.59, p<$ $0.01 ; * p<0.01$ for HA-rSac3-PC12 cells versus normal PC12 cells, HA-pcDNA3-PC12 cells or HA-rSac3-D491V-PC12 cells $(n$ $=160$, one-way ANOVA, followed by Fisher LSD analysis). The scale bar indicates $100 \mu \mathrm{m}$.

brain cDNA library, and examined its effect on the cellular growth and differentiation of PC12 cells. The major findings of this study are as follows: (1) the newly identified Sac-domain-containing protein, rSac3, shows PIPPase activity with $\mathrm{PI}(3) \mathrm{P}, \mathrm{PI}(4) \mathrm{P}$ and $\mathrm{PI}(3,5) \mathrm{P}_{2}$ as substrates in vitro, and a site-specific mutation in the catalytic core of rSac3 abolishes its enzymatic activity; (2) rSac3 localizes to the ER, Golgi complex and recycling endosomes; (3) 
rSac3 expression is upregulated during NGF-stimulated PC12 cell neuronal differentiation, and overexpression of this protein could promote neurite outgrowth in PC12 cells; and (4) the inhibition of rSac3 expression by antisense oligonucleotide reduces the neurite outgrowth of PC12 cells, and mutation in the catalytic sequence of rSac3 eliminates its neurite-outgrowth-promoting activity. Taken together, these results suggest that $\mathrm{rSac} 3$, functioning as a PIPPase, participates in forward membrane trafficking from the ER and Golgi to the PM, and helps essential components to promote neurite outgrowth.

\section{Substrate specificity of $r \mathrm{Sac} 3$}

It has been shown that the substrate specificity of the Sac domain PIPPases may not always be the same between in vitro and in vivo studies. Different phosphoinositides localize to distinct intracellular compartments. They influence membrane trafficking via their structural role as membrane components and via their high affinity and specificity binding to membrane trafficking associated proteins [45-47]. Similarly, the distinct subcellular localization of the Sacdomain-containing proteins also limits their accessibility to specific phosphoinositides. For example, synaptojanin 1 can use various phosphoinositides as substrates in vitro [31], but in vivo it limits its localization to the endocytic intermediates [14-18]. This is the place where $\mathrm{PI}(4,5) \mathrm{P}_{2}$ is concentrated [48, 49], so synaptojanin 1 can utilize $\mathrm{PI}(4,5) \mathrm{P}_{2}$ as the substrate in vivo. As for yeast $\mathrm{Sac} 1 \mathrm{p}$, the Golgi localization restricts its substrate specificity to only $\mathrm{PI}(4) \mathrm{P}$, through which it regulates Golgi trafficking in yeast cells $[25,26]$. In our study, we observed that rSac3 localization formed a gradient from the ER and Golgi complex, through the trans-Golgi network, to the recycling endosomes (Figure 3). Thus, the possible substrate(s) for rSac3 in vivo would include the phosphoinositides that are concentrated in the ER, Golgi complex and ER-Golgirelated compartments. The main phosphoinositide in the ER and Golgi complex is PI(4)P, which participates in maintaining the ER and Golgi structure and regulating the vesicles that are exported from the trans-Golgi network to the PM [50]. As for $\mathrm{PI}(3) \mathrm{P}$ and $\mathrm{PI}(3,5) \mathrm{P}_{2}$, the former has been detected primarily in the early endosomes [51], and the latter is in multivesicular endosomes on the yeast vacuoles (the mammalian counterparts are lysosomes) [52, 53]. Based on these observations, we speculate that rSac 3 might use PI(4)P as its substrate in vivo.

\section{Catalytic region of $r \mathrm{Sac} 3$}

A previous study on the catalytic core of Sac domain PIPPase has shown that the conserved sequence, RXNCV(L)DCLDRTN, within the sixth motif of the Sac domain is important for the enzymatic activity [10].
Amino-acid replacement of cysteine at the first position, arginine at the second position and threonine abolishes the enzymatic activity of the Sac-domain-containing protein Inp51. The site-specific mutation of the first cysteine within this conserved sequence of $\mathrm{hSac} 1$ protein also blocks PIPPase activity [23]. The replacement of the first aspartic acid by asparagine in the same sequence of $\mathrm{rSac} 1$ protein reduces its phosphatase activity to $\mathrm{PI}(4) \mathrm{P}$, but retains its enzymatic activity to $\mathrm{PI}(3) \mathrm{P}$ and $\mathrm{PI}(3,5) \mathrm{P}_{2}$ [54]. Given that the Sac domain of rSac3 also shows PIPPase activity in vitro, we wondered whether other amino acids within this sequence also contribute to the enzymatic activity of rSac3. We introduced a new site-specific mutation by replacing aspartic acid at the second position with valine (the D491V mutation). When we measured the effects of this mutation on the PIPPase activity of rSac3, we were surprised that this new site-specific mutation totally abolished the enzyme activity of rSac3 (Figure 4). This is the first demonstration that the aspartic acid at the second position within this sequence is essential for the PIPPase activity of the Sac domain. These results further support the notion that this conserved sequence is the catalytic core of Sac domain phosphatases, in which a single amino-acid mutation may impair the enzymatic activity of the Sac-domain-containing proteins.

\section{Possible function of $r \mathrm{Sac} 3$}

Neurite outgrowth is a key feature of neuronal differentiation and is essential for the establishment of synaptic connections during the development of the nervous system. The outgrowth of neurite from the soma greatly expands the membrane area of the cell surface. Therefore, massive membrane components, such as membrane lipids and membrane proteins, need to be synthesized in the ER lumen and transported from the Golgi complex, through the transGolgi network-derived exocytic vesicles, to the PM. Most members of Sac domain PIPPases function in intracellular membrane trafficking $[6,20,27]$. In yeast, Sac1p is an important regulator for maintaining the secretory function of ER by controlling the supply of ATP inside the ER lumen [27]. In synaptojanin 1 mutant mice, the clathrin-coated vesicles accumulate in the cytomatrix-rich area that surrounds the synaptic vesicle cluster in nerve endings, which suggests that synaptojanin 1 facilitates the progression of recycling vesicles back to the synaptic vesicle pool $[6,19]$. Here, we show that $\mathrm{rSac} 3$ can affect the neurite outgrowth of NGF-stimulated PC12 cells, and that this function is dependent on the enzymatic activity of PIPPase (Figures 5 and 6). In contrast to synaptojanin $1, \mathrm{rSac} 3$ colocalizes with markers specific for organelles including ER, Golgi complex and recycling endosomes (Figure 3), suggesting that $\mathrm{rSac} 3$ probably participates in forward membrane 
trafficking. Previous work has also indicated that other PIPPases, such as inositol polyphosphate 5-phosphatase and PTEN, function as $\mathrm{PI}(3) \mathrm{K}$ pathway inhibitors and inhibit neurite outgrowth in $\mathrm{PC} 12$ cells $[55,56]$. Considering that both of these two PIPPases are not Sac domain proteins and hydrolyze $\mathrm{PI}(3,4,5) \mathrm{P}_{3}$, our work reveals that $\mathrm{rSac} 3$ is a 3-Pi and 4-Pi PIPPase, and may promote neurite outgrowth through a different pathway. That is, $\mathrm{rSac} 3$, as a mammalian Sac domain PIPPase, modulates the PI(4)P pool in the ER and Golgi complex, thus regulating forward membrane trafficking from the ER and Golgi complex to the PM to promote the neurite outgrowth of differentiating neurons. This role of rSac3 also suggests that Sac domain PIPPase proteins may participate in forward membrane trafficking from the ER and Golgi complex to the PM, thus functioning as regulators of this crucial process of neuronal cell growth and differentiation.

\section{Acknowledgments}

We thank Dr Bin Zhang (University of Michigan, USA) for providing the MCFD2 antibodies. This work was supported in part by the Life Science Special Fund of the Chinese Academy of Sciences for Human Genome Research (KJ95T-06 and KSCX1-Y02 to BML, NHJ and MLJ), the National Natural Science Foundation of China (30225023 and 30430240 to BML and 90208011, 30300174, 30470856, 30421005 and 30623003 to NHJ), the National Key Basic Research and Development Program of China (2006CB500807 to BML and 2002CB713802, 2005 CB522704 and 2006CB943902 to NHJ), the National High-Tech Research and Development Program of China (2006AA02Z199 to BML and 2006AA02Z186 to NHJ), the Shanghai Key Project of Basic Science Research (04DZ14005 to BML and 04DZ14005, 04DZ05608, 06DJ14001 and 06DZ22032 to NHJ), the Council of the Shanghai Municipal for Science and Technology (05814578 to NHJ), and the US National Institutes of Health (DA013471 and DA020555 to LY).

\section{References}

1 Maxfield FR, McGraw TE. Endocytic recycling. Nat Rev Mol Cell Biol 2004; 5:121-132.

2 Marsh M, McMahon HT. The structural era of endocytosis. Science 1999; 285:215-220.

3 Ringstad N, Gad H, Low P, et al. Endophilin/SH3p4 is required for the transition from early to late stages in clathrin-mediated synaptic vesicle endocytosis. Neuron 1999; 24:143-154.

4 De Camilli P, Takei K. Molecular mechanisms in synaptic vesicle endocytosis and recycling. Neuron 1996; 16:481-486.

5 Sever S, Damke H, Schmid SL. Dynamin:GTP controls the formation of constricted coated pits, the rate limiting step in clathrin-mediated endocytosis. J Cell Biol 2000; 150:1137-1148.
6 Cremona O, Di Paolo G, Wenk MR, et al. Essential role of phosphoinositide metabolism in synaptic vesicle recycling. Cell 1999; 99:179-188.

7 Griffiths G, Hoflack B, Simons K, Mellman I, Kornfeld S. The mannose 6-phosphate receptor and the biogenesis of lysosomes. Cell 1988; 52:329-341.

8 Duden R. ER-to-Golgi transport: COP I and COP II function (Review). Mol Membr Biol 2003; 20:197-207.

9 Godi A, Di Campli A, Konstantakopoulos A, et al. FAPPs control Golgi-to-cell-surface membrane traffic by binding to ARF and PtdIns(4)P. Nat Cell Biol 2004; 6:393-404.

10 Hughes WE, Cooke FT, Parker PJ. Sac phosphatase domain proteins. Biochem J 2000; 350(Part 2):337-352.

11 Haffner C, Takei K, Chen H, et al. Synaptojanin 1: localization on coated endocytic intermediates in nerve terminals and interaction of its $170 \mathrm{kDa}$ isoform with Eps15. FEBS Lett 1997; 419:175-180.

12 Nemoto Y, Arribas M, Haffner C, DeCamilli P. Synaptojanin 2, a novel synaptojanin isoform with a distinct targeting domain and expression pattern. J Biol Chem 1997; 272:30817-30821.

13 Stolz LE, Huynh CV, Thorner J, York JD. Identification and characterization of an essential family of inositol polyphosphate 5-phosphatases (INP51, INP52 and INP53 gene products) in the yeast Saccharomyces cerevisiae. Genetics 1998; 148:17151729.

14 de Heuvel E, Bell AW, Ramjaun AR, et al. Identification of the major synaptojanin-binding proteins in brain. J Biol Chem 1997; 272:8710-8716.

15 Qualmann B, Roos J, DiGregorio PJ, Kelly RB. Syndapin I, a synaptic dynamin-binding protein that associates with the neural Wiskott-Aldrich syndrome protein. Mol Biol Cell 1999; 10:501513.

16 Ringstad N, Nemoto Y, De Camilli P. The SH3p4/Sh3p8/SH3p13 protein family: binding partners for synaptojanin and dynamin via a Grb2-like Src homology 3 domain. Proc Natl Acad Sci USA 1997; 94:8569-8574.

17 David C, McPherson PS, Mundigl O, de Camilli P. A role of amphiphysin in synaptic vesicle endocytosis suggested by its binding to dynamin in nerve terminals. Proc Natl Acad Sci USA 1996; 93:331-335.

18 Hussain NK, Jenna S, Glogauer M, et al. Endocytic protein intersectin-1 regulates actin assembly via Cdc42 and N-WASP. Nat Cell Biol 2001; 3:927-932.

19 Kim WT, Chang S, Daniell L, et al. Delayed reentry of recycling vesicles into the fusion-competent synaptic vesicle pool in synaptojanin 1 knockout mice. Proc Natl Acad Sci USA 2002; 99:17143-17148.

20 Rusk N, Le PU, Mariggio S, et al. Synaptojanin 2 functions at an early step of clathrin-mediated endocytosis. Curr Biol 2003; 13:659-663.

21 Novick P, Botstein D. Phenotypic analysis of temperature-sensitive yeast actin mutants. Cell 1985; 40:405-416.

22 Erdman S, Lin L, Malczynski M, Snyder M. Pheromone-regulated genes required for yeast mating differentiation. J Cell Biol 1998; 140:461-483.

23 Rohde HM, Cheong FY, Konrad G, et al. The human phosphatidylinositol phosphatase SAC1 interacts with the coatomer I complex. J Biol Chem 2003; 278:52689-52699.

24 Minagawa T, Ijuin T, Mochizuki Y, Takenawa T. Identification 
and characterization of a sac domain-containing phosphoinositide 5-phosphatase. J Biol Chem 2001; 276:22011-22015.

25 Tahirovic S, Schorr M, Mayinger P. Regulation of intracellular phosphatidylinositol-4-phosphate by the Sac1 lipid phosphatase. Traffic 2005; 6:116-130.

26 Foti M, Audhya A, Emr SD. Sac1 lipid phosphatase and Stt4 phosphatidylinositol 4-kinase regulate a pool of phosphatidylinositol 4-phosphate that functions in the control of the actin cytoskeleton and vacuole morphology. Mol Biol Cell 2001; 12:2396-2411.

27 Kochendorfer KU, Then AR, Kearns BG, Bankaitis VA, Mayinger P. Sac1p plays a crucial role in microsomal ATP transport, which is distinct from its function in Golgi phospholipid metabolism. EMBO J 1999; 18:1506-1515.

28 Konrad G, Schlecker T, Faulhammer F, Mayinger P. Retention of the yeast Saclp phosphatase in the endoplasmic reticulum causes distinct changes in cellular phosphoinositide levels and stimulates microsomal ATP transport. J Biol Chem 2002; 277:10547-10554.

29 Rudge SA, Anderson DM, Emr SD. Vacuole size control: regulation of PtdIns (3,5)P2 levels by the vacuole-associated Vac14Fig4 complex, a PtdIns(3,5)P2-specific phosphatase. Mol Biol Cell 2004; 15:24-36.

30 Duex JE, Tang F, Weisman LS. The Vac14p-Fig4p complex acts independently of Vac7p and couples PI3,5P2 synthesis and turnover. J Cell Biol 2006; 172:693-704.

31 Jin M, Wang XM, Tu Y, et al. The negative cell cycle regulator, Tob (transducer of ErbB-2), is a multifunctional protein involved in hippocampus-dependent learning and memory. Neuroscience 2005; 131:647-659.

32 Hou Q, Gao X, Zhang X, et al. SNAP-25 in hippocampal CA1 region is involved in memory consolidation. Eur J Neurosci 2004; 20:1593-1603.

33 Piper RC, Hess LJ, James DE. Differential sorting of two glucose transporters expressed in insulin-sensitive cells. Am J Physiol 1991; 260(Part 1):C570-C580.

34 Wang C, Xia C, Bian W, et al. Cell aggregation-induced FGF8 elevation is essential for $\mathrm{P} 19$ cell neural differentiation. Mol Biol Cell 2006; 17:3075-3084.

35 Nyfeler B, Zhang B, Ginsburg D, Kaufman RJ, Hauri HP. Cargo selectivity of the ERGIC-53/MCFD2 transport receptor complex. Traffic 2006; 7:1473-1481.

36 Maehama T, Taylor GS, Slama JT, Dixon JE. A sensitive assay for phosphoinositide phosphatases. Anal Biochem 2000; 279:248250.

37 Mandal DK, Brewer CF. Differences in the binding affinities of dimeric concanavalin A (including acetyl and succinyl derivatives) and tetrameric concanavalin A with large oligomannosetype glycopeptides. Biochemistry 1993; 32:5116-5120.

38 Mitranic MM, Sturgess JM, Moscarello MA. The effect of wheat germ agglutinin on sialyl and galactosyltransferases of rat liver Golgi membranes. Can J Biochem 1979; 57:1008-1013.

39 Urbe S, Huber LA, Zerial M, Tooze SA, Parton RG. Rab11, a small GTPase associated with both constitutive and regulated secretory pathways in PC12 cells. FEBS Lett 1993; 334:175182.
40 Ullrich O, Reinsch S, Urbe S, Zerial M, Parton RG. Rab11 regulates recycling through the pericentriolar recycling endosome. J Cell Biol 1996; 135:913-924.

$41 \mathrm{Mu}$ FT, Callaghan JM, Steele-Mortimer O, et al. EEA1, an early endosome-associated protein. EEA1 is a conserved alpha-helical peripheral membrane protein flanked by cysteine "fingers" and contains a calmodulin-binding IQ motif. J Biol Chem 1995; 270:13503-13511.

42 Parton RG. Caveolae and caveolins. Curr Opin Cell Biol 1996; 8:542-548.

43 Gilmore K, Wilson M. The use of chloromethyl-X-rosamine (Mitotracker red) to measure loss of mitochondrial membrane potential in apoptotic cells is incompatible with cell fixation. Cytometry 1999; 36:355-358.

44 Price OT, Lau C, Zucker RM. Quantitative fluorescence of 5-FUtreated fetal rat limbs using confocal laser scanning microscopy and Lysotracker Red. Cytometry A 2003; 53:9-21.

45 Lemmon MA. Phosphoinositide recognition domains. Traffic 2003; 4:201-213.

46 Gaullier JM, Simonsen A, D'Arrigo A, et al. FYVE fingers bind PtdIns(3)P. Nature 1998; 394:432-433.

47 Cullen PJ, Cozier GE, Banting G, Mellor H. Modular phosphoinositide-binding domains - their role in signalling and membrane trafficking. Curr Biol 2001; 11:R882-R893.

48 Watt SA, Kular G, Fleming IN, Downes CP, Lucocq JM. Subcellular localization of phosphatidylinositol 4,5-bisphosphate using the pleckstrin homology domain of phospholipase $\mathrm{C}$ delta1. Biochem J 2002; 363(Part 3):657-666.

49 Cremona O, De Camilli P. Phosphoinositides in membrane traffic at the synapse. J Cell Sci 2001; 114(Part 6):1041-1052.

50 Wang YJ, Wang J, Sun HQ, et al. Phosphatidylinositol 4 phosphate regulates targeting of clathrin adaptor AP-1 complexes to the Golgi. Cell 2003; 114:299-310.

51 Gillooly DJ, Morrow IC, Lindsay M, et al. Localization of phosphatidylinositol 3-phosphate in yeast and mammalian cells. EMBO J 2000; 19:4577-4588.

52 Shaw JD, Hama H, Sohrabi F, DeWald DB, Wendland B. PtdIns(3,5)P2 is required for delivery of endocytic cargo into the multivesicular body. Traffic 2003; 4:479-490.

53 Friant S, Pecheur EI, Eugster A, et al. Ent3p Is a PtdIns(3,5)P2 effector required for protein sorting to the multivesicular body. Dev Cell 2003; 5:499-511.

54 Nemoto Y, Kearns BG, Wenk MR, et al. Functional characterization of a mammalian Sac1 and mutants exhibiting substratespecific defects in phosphoinositide phosphatase activity. J Biol Chem 2000; 275:34293-34305.

55 Musatov S, Roberts J, Brooks AI, et al. Inhibition of neuronal phenotype by PTEN in PC12 cells. Proc Natl Acad Sci USA 2004; 101:3627-3631.

56 Ooms LM, Fedele CG, Astle MV, et al. The inositol polyphosphate 5-phosphatase, PIPP, is a novel regulator of phosphoinositide 3-kinase-dependent neurite elongation. Mol Biol Cell 2006; 17:607-622.

(Supplementary Information is linked to the online version of the paper on the Cell Research website.) 